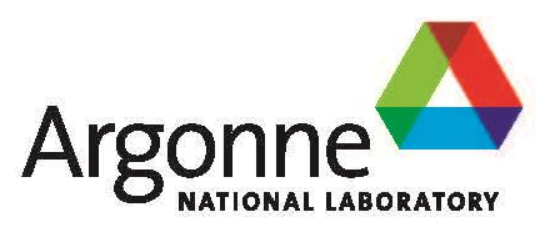

ANL/NE-15/18

\title{
Design and Testing of Subsystems for Mo-99 Production Facility
}

Nuclear Engineering Division 


\begin{abstract}
About Argonne National Laboratory
Argonne is a U.S. Department of Energy laboratory managed by UChicago Argonne, LLC under contract DE-AC02-06CH11357. The Laboratory's main facility is outside Chicago, at 9700 South Cass Avenue, Argonne, Illinois 60439. For information about Argonne and its pioneering science and technology programs, see www.anl.gov.
\end{abstract}

\title{
DOCUMENT AVAILABILITY
}

Online Access: U.S. Department of Energy (DOE) reports produced after 1991 and a growing number of pre-1991 documents are available free via DOE's SciTech Connect (http://www.osti.gov/scitech/).

Reports not in digital format may be purchased by the public from the National Technical Information Service (NTIS):

U.S. Department of Commerce

National Technical Information Service

5301 Shawnee Road

Alexandria, VA 22312

unw.ntis.gov

Phone: (800) 553-NTIS (6847) or (703) 605-6000

Fax: (703) 605-6900

Email: orders@ntis.gov

Reports not in digital format are available to DOE and DOE contractors from the Office of Scientific and Technical Information (OST):

U.S. Department of Energy

Office of Scientific and Technical Information

P.O. Box 62

Oak Ridge, TN 37831-0062

unw.osti.gov

Phone: (865) 576-8401

Fax: (865) 576-5728

Email: reports@osti.gov

\section{Disclaimer}

This report was prepared as an account of work sponsored by an agency of the United States Government. Neither the United States Government nor any agency thereof, nor UChicago Argonne, LLC, nor any of their employees or officers, makes any warranty, express or implied, or assumes any legal liability or responsibility for the accuracy, completeness, or usefulness of any information, apparatus, product, or process disclosed, or represents that its use would not infringe privately owned rights. Reference herein to any specific commercial product, process, or service by trade name, trademark, manufacturer, or otherwise, does not necessarily constitute or imply its endorsement, recommendation, or favoring by the United States Government or any agency thereof. The views and opinions of document authors expressed herein do not necessarily state or reflect those of the United States Government or any agency thereof, Argonne National Laboratory, or UChicago Argonne, LLC. 


\section{Design and Testing of Subsystems for Mo-99 Production Facility}

by

Sergey Chemerisov, James Bailey, Mathew Virgo, Roman Gromov, Vakho Makarashvili, and Brad Micklich

Nuclear Engineering Division, Argonne National Laboratory

prepared for

U.S. Department of Energy, National Nuclear Security Administration, Office of Defense Nuclear Nonproliferation

October 2014 



\section{CONTENTS}

INTRODUCTION

2 BEAM DIAGNOSTICS

2.1 Destructive Beam Diagnostics ................................................................. 3

2.1.1 Optical Transition Radiation and Infrared Cameras............................... 3

2.1.2 Beam Collimator ............................................................................ 3

2.1.3 Heat Transfer Thermal Analysis for the Collimator .............................. 5

2.1.4 Beam Stop ............................................................................... 5

2.2 Non-destructive Diagnostic Beam Position Monitors — Installation and Testing. 7

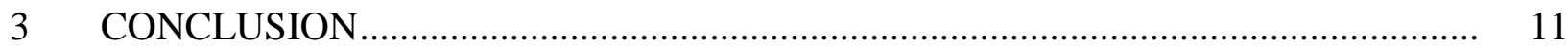

APPENDIX A: $\quad 10^{\circ}$-Magnet Beam Line for the Mo-99 Production Facility ...................... 13

APPENDIX B: Alpha Magnet Beamline for the Mo-99 Production Facility .................... 25

APPENDIX C: Preliminary Heat Transfer Analysis ................................................. 33

\section{FIGURES}

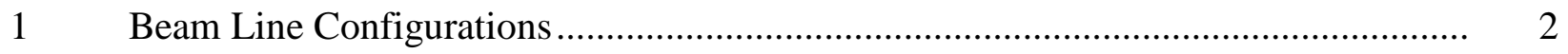

$2 \quad$ Water-Cooled Collimator Design Used at Argonne ......................................... 4

3 Conceptual Design of the Segmented Collimator............................................. 5

4 One-Dimensional Model for Heat Transfer in the Collimator Wall......................... 6

$5 \quad$ High Power Beam Stop Designed and Tested at Argonne ................................... 6

$6 \quad$ Concept of the Multi-Element Beam Stop for Production Facility …...................... 7

$7 \quad$ Pickup with Standard 4.5-in. CF Flanges Provided by LANL …............................ 8

8 Pickup Installed at the Beam Transport Channel and Hooked Up with Signal

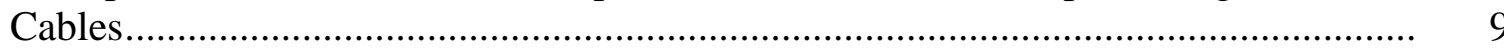

$9 \quad$ BPM's Control Electronics Installed in 19 in. Standard Rack................................ 9 


\section{FIGURES (Cont.)}

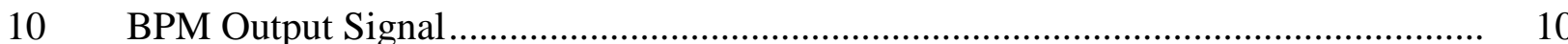

A.1 Proposed Layout of Beam Transport System ….................................................. 15

A.2 Initial Beam Profile and Subsequent Beam Profile on the Target ........................... 16

A.3 Beam Transverse Profile in Raster Magnet and Before Third Quadrupole................ 17

A.4 Magnetic Field Strength Across Raster-Magnet Cross Section................................. 19

A.5 Cross Section of the Raster Magnet...................................................................... 19

A.6 Transverse Magnetic Field in the Pole Gap ...................................................... 21

A.7 Transverse Cross Section of Bending Magnet.................................................. 21

A.8 Top View of Bending Magnet ...................................................................... 22

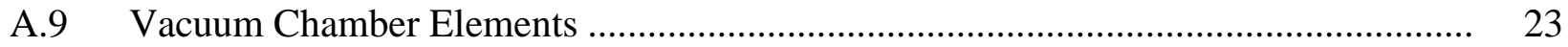

A.10 Port Cross-Section for Beam Position Monitoring ............................................... 23

B.1 Schematic Representation of the Beamline for the $9-\mu \mathrm{m}$ and $50-\mu \mathrm{m}$ Cases .............. 28

B.2 Beam Profile for the Case with 50- $\mu \mathrm{m}$ Emittance and $\pm 5 \%$ Energy Spread ............... 29

B.3 Spot Size on Target in $\mathrm{x}$ and $\mathrm{y}$ Directions for Each Combination of Emittance and Energy Spread Considered .......................................................................................... 30

B.4 Preliminary Design for the Alpha Magnet Cross Section.................................... 31

B.5 Probability for a Given Cumulative Higher Order Contribution to $\mathrm{x}^{\prime}$ for Two Ranges of $y^{\prime}$ 


\section{DESIGN AND TESTING OF SUBSYSTEMS FOR Mo-99 PRODUCTION FACILITY}

\section{INTRODUCTION}

So far, three beamline configurations have been proposed for the SHINE Medical Technologies facility for producing fission-product ${ }^{99}$ Mo using a D/T-accelerator (Figure 1). One configuration, proposed by Los Alamos National Laboratory (LANL), includes a three-bend magnet system with a total $20^{\circ}$ bending angle. This configuration also includes a set of octuplet magnets to generate a non-Gaussian beam profile. Argonne has proposed two beamlines based on a (1) $10^{\circ}$ bending magnet (Appendix A and Ref. 1) and (2) alpha magnets (Appendix B) that use a pair of raster doublets to redistribute the beam over the face of the target. While those configurations are quite different, and each of the configurations has its advantages and disadvantages, they all have to incorporate the means to verify beam parameters before placing the beam on the target, monitor beam position and shape during a run, protect the target housing from the overheating due to beam displacement, and protect the beamlines from overheating due to beam misalignment.

Because each beamline design includes at least one bending magnet, one can use the same magnet as an energy analyzer. The design of the energy analyzer will depend on the beamline design choice for the production facility and will be studied in FY 2015, when the final choice for the beamline configuration will have been made. 

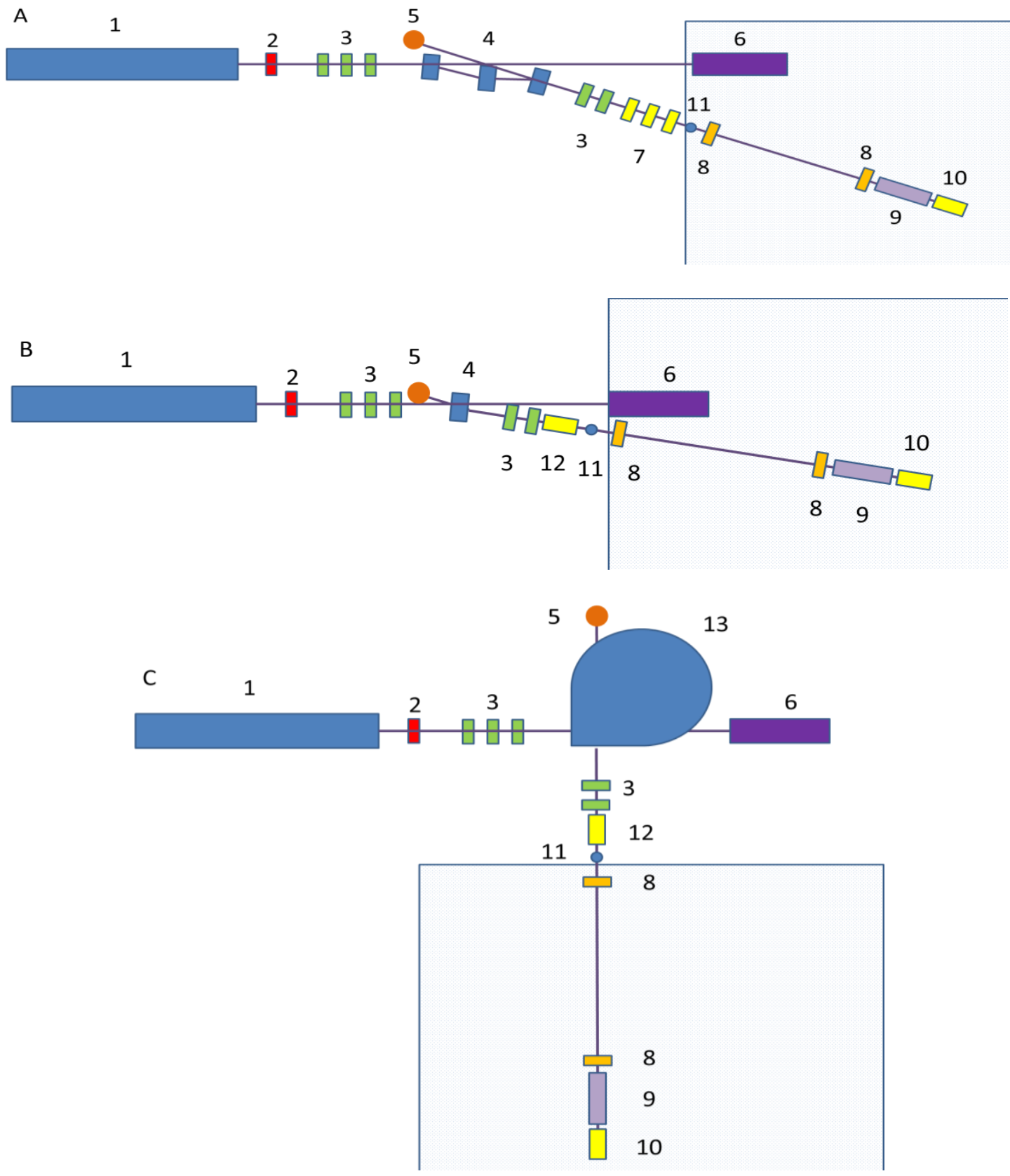

FIGURE 1 Beam Line Configurations: A was Proposed by LANL; B and C were Proposed by Argonne. Beam line elements:

1- Linac

2- Fast Acting Gate Valve

3- Quad Magnets

4- Bending Magnet

5- OTR and IR Cameras
6- Beam Stop

7- Non-linear Beam Optics

8- Beam-Position Monitors

9- Collimator

10- Target
11- Gate-Valve Vacuum Sensor

12- Rastering Magnet

13- Alpha Magnet

Beam line elements are not drawn to scale. 


\section{BEAM DIAGNOSTICS}

Beam diagnostic elements can be divided into two types-destructive and nondestructive. They are discussed separately below.

\subsection{DESTRUCTIVE BEAM DIAGNOSTICS}

For destructive beam diagnostics, the whole or part of the beam is intercepted to produce an electrical or optical signal proportional to the current density. Most destructive diagnostic components can be used only during the tuneup operation because they disturb the beam profile. The only notable exception is an optical transition radiation (OTR) monitoring system, which uses light emitted by high-energy electrons impacting a target window. Because the window separates the vacuum and coolant sides of the target, it is in place during normal operation.

\subsubsection{Optical Transition Radiation and Infrared Cameras}

Testing of the OTR and infrared (IR) cameras has continued in the first half of FY 2014 at our Van de Graaff (VDG) accelerator. A separate report, with Argonne participation, on camera performance will be issued by LANL. During experimental runs at the Argonne linac facility, the cameras will be exposed to a mixed radiation field of x-rays and neutrons. We have experienced camera failure in the past, so for future runs, we plan to measure radiation exposure for the cameras to establish a correlation between dose to the cameras and their performance. For each run, a series of dosimeters will be placed around the camera enclosures and also will be directly attached to the camera. Dosimeter sets consist of a set of neutron-activation dosimeters (wires and foils) and x-ray dosimeter from Landauer. After each experiment, the dosimeters will be analyzed, and a dose will be assigned to the camera; therefore, in the event of failure, we will be able to calculate the dose that caused the failure. This work will start in FY 2015.

\subsubsection{Beam Collimator}

During irradiation runs at the Argonne linac facility, we noticed that the position of the beam can significantly change during the run due to variation in beam energy. When the beam misses the target window, the temperature can increase outside the safety temperature envelope for the target housing. In the Argonne linac, this temperature increase is not large enough to have potential for damaging the target holder, but in the production facility, the consequence of the misalignment can be catastrophic. To prevent this possibility, a beam collimator was proposed. The main purpose of the collimator is to limit the size of the beam, so the simple collimator is a water-cooled narrow piece of the beam line that will protect the target housing. Because this simple collimator is physically connected to the beamline, it is impossible to know how much beam is lost. For a collimator to be used for beam diagnosis, it has to be electrically insulated from the beam line. Insulation is usually done with ceramic breaks. We used this arrangement at the Argonne linac; drawings of the collimator are shown in Figure 2. 


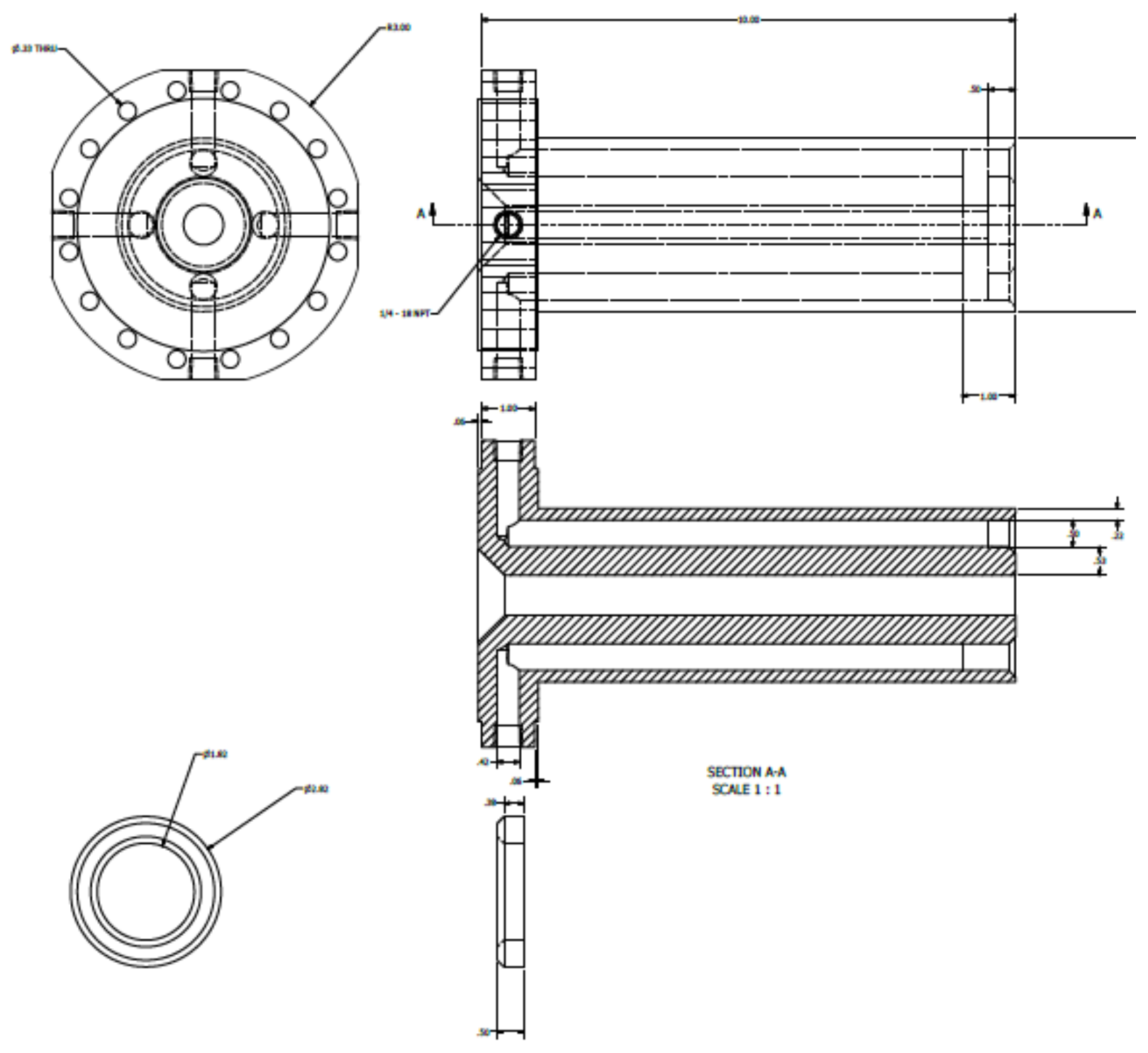

FIGURE 2 Water-Cooled Collimator Design Used at Argonne

We measure current on the collimator to ensure that the beam is centered on the target. During the run, this electrical signal is measured, and the completion of the accelerator interlock chain is interrupted when the signal becomes too large. A similar arrangement can be employed at the production facility.

While this collimator can be used in target protection interlocks, it does not provide information on the direction of the beam displacement or the beam shape. To that end, we are proposing to use a segmented collimator shown in Figure 3. This collimator consists of four electrically insulated segments. Because the signal from each of the segments can be measured independently, position and asymmetry of the beam can be established. In FY 2015, we will fabricate a prototype of the segmented collimator and test it with the beam at the Argonne linac. 


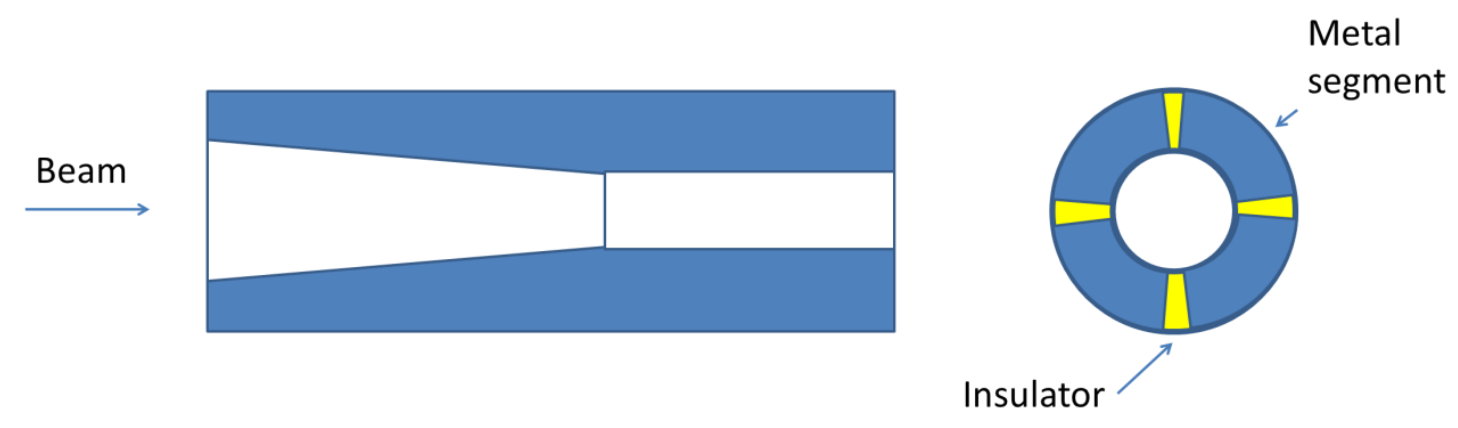

FIGURE 3 Conceptual Design of the Segmented Collimator

\subsubsection{Heat Transfer Thermal Analysis for the Collimator}

A 1-D calculation for heat dissipation in a collimator is presented in Appendix C. Figure 4 illustrates the model for this calculation. The results of this study show that the avoidance of boiling of the coolant (water) at the wall is clearly the limiting factor. At $100^{\circ} \mathrm{C}$ wall temperature, the maximum wall thickness is calculated to be $0.066 \mathrm{~cm}(0.026 \mathrm{in}$.) for an aluminum wall. The maximum aluminum temperature is $102.4^{\circ} \mathrm{C}$, which is not a concern. A second calculation was performed for a stainless steel wall tube. The results of this analysis indicated a maximum wall thickness of $0.024 \mathrm{~cm}(0.0094$ in.) with a maximum stainless steel temperature of $112.7^{\circ} \mathrm{C}$. As one can see from the numbers above, either of these ordinary materials is marginally suitable for collimator construction. Extruded aluminum profiles are available with walls as thin as $0.05 \mathrm{~cm}$, but possible corrosion in a high radiation field will reduce the service life of the collimator. We are planning to build and test a thin-wall aluminum collimator and test it with an electron beam. As an alternative, if one limits the amount of beam deposited at the collimator by using a sufficiently fast interlock system, the thickness of the collimator walls can be increased.

Another promising material for the collimator is beryllium. It has lower density, a higher thermal conductivity, and higher melting temperature compared with aluminum. The disadvantage of the beryllium collimator is the cost and possible health effects if this material gets airborne. The advantages of this material can overweigh the negative factors, especially if it can significantly increase the system reliability.

\subsubsection{Beam Stop}

A beam stop will be used during the tuneup of the beam before placing the target into the beamline. The design challenges here are even tougher than those for the collimator design. Figure 5 is a schematic of a high-power beam stop designed and tested at the Argonne linac facility. This beam stop is fabricated of aluminum and cooled with water. Beam power for this collimator is limited to $10 \mathrm{~kW}$, which is an order of magnitude lower than that required for tuning the full-power beam at the production facility. One would also need to collect beamprofile information from the beam stop. To accomplish this, we propose to use a dispersion 


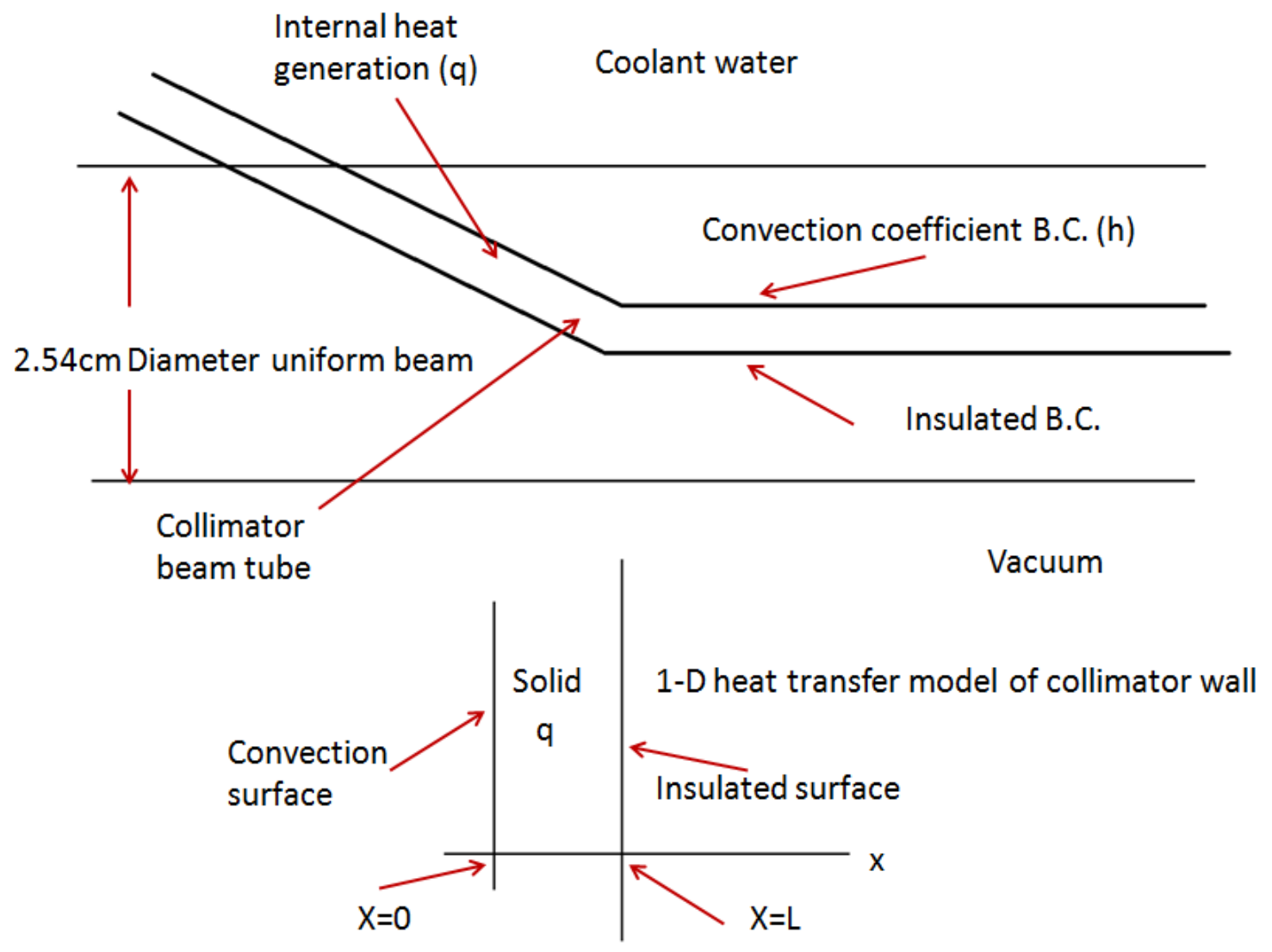

FIGURE 4 One-Dimensional Model for Heat Transfer in the Collimator Wall
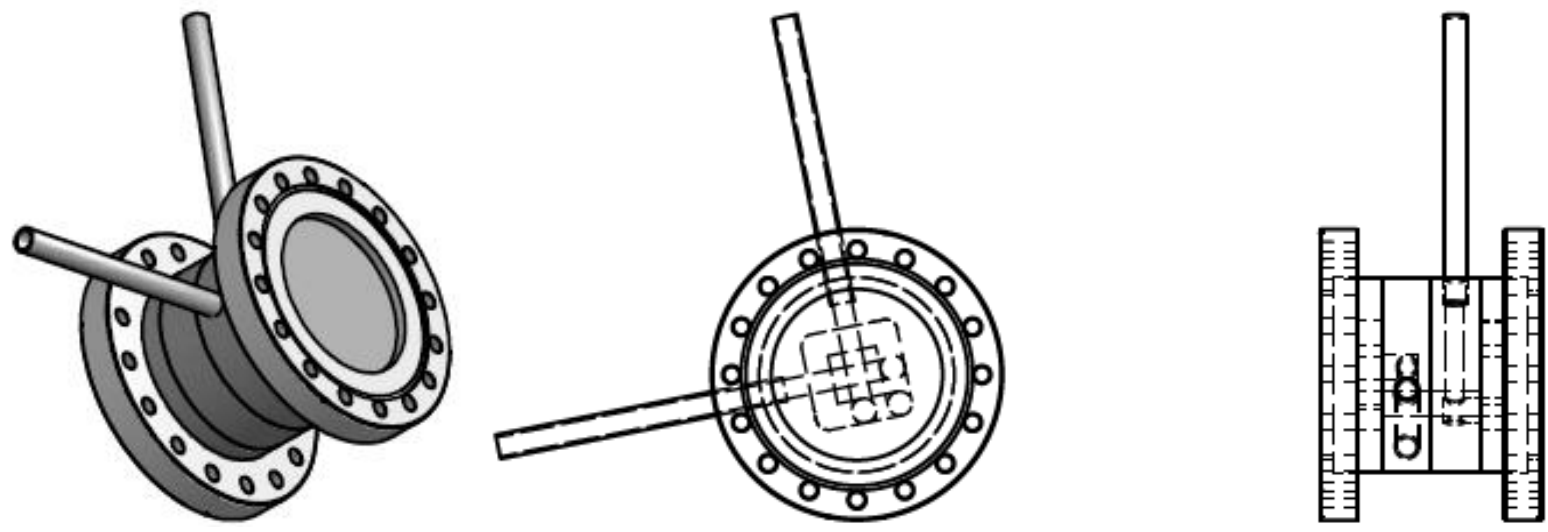

FIGURE 5 High Power Beam Stop Designed and Tested at Argonne 
element (solenoid) to spread the beam and a multi-element beam stop assembly (Figure 6).

Design for this type of beam stop is under way, and a prototype will be tested in December 2014.

\subsection{NON-DESTRUCTIVE DIAGNOSTIC BEAM POSITION MONITORS - INSTALLATION AND TESTING}

Beam position monitors (BPMs) are widely used for non-destructive diagnostics by nearly all accelerators in the world. They estimate the center of mass of the beam and can be used to measure the total beam current and longitudinal bunch shape. The control electronics measure the charge induced by the electric field of the charged-particle beam on an insulated metal plate. To determine the beam position, four plates are installed crosswise at the beam pipe. The displacement is measured directly by calculation of

$$
\mathrm{dX}=\mathrm{Kx} \cdot \log (\mathrm{U} 1 / \mathrm{U} 2)
$$

where $\mathrm{dX}=$ beam displacement from the center of BPM, $\mathrm{Kx}=$ multiplication factor, and $\mathrm{U} 1$ and $\mathrm{U} 2$ = signal amplitude from the opposite plates.

Signals from separate channels are processed simultaneously by electronics synchronized with the beam pulse. Each channel has an input band-pass filter, followed by an amplification chain.

The system of three BPMs was designed for the Low Energy Linac Facility at Argonne with assistance from LANL. It consists of pickups, control electronics, and signal cables. The four-plated pickup is incorporated into a standard 4.5-in. CF flange (Figure 7). These pickups were designed and provided for our tests by LANL. Each pickup is installed in a $45^{\circ}$-rotated

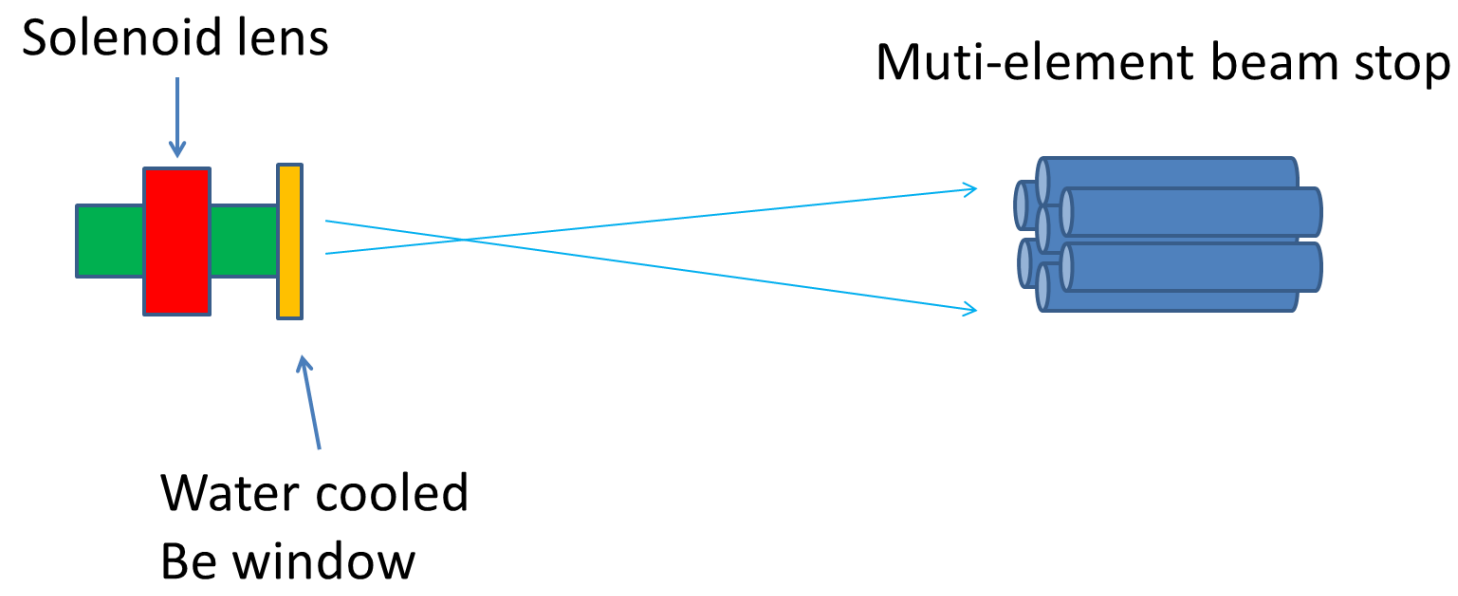

FIGURE 6 Concept of the Multi-Element Beam Stop for Production Facility 


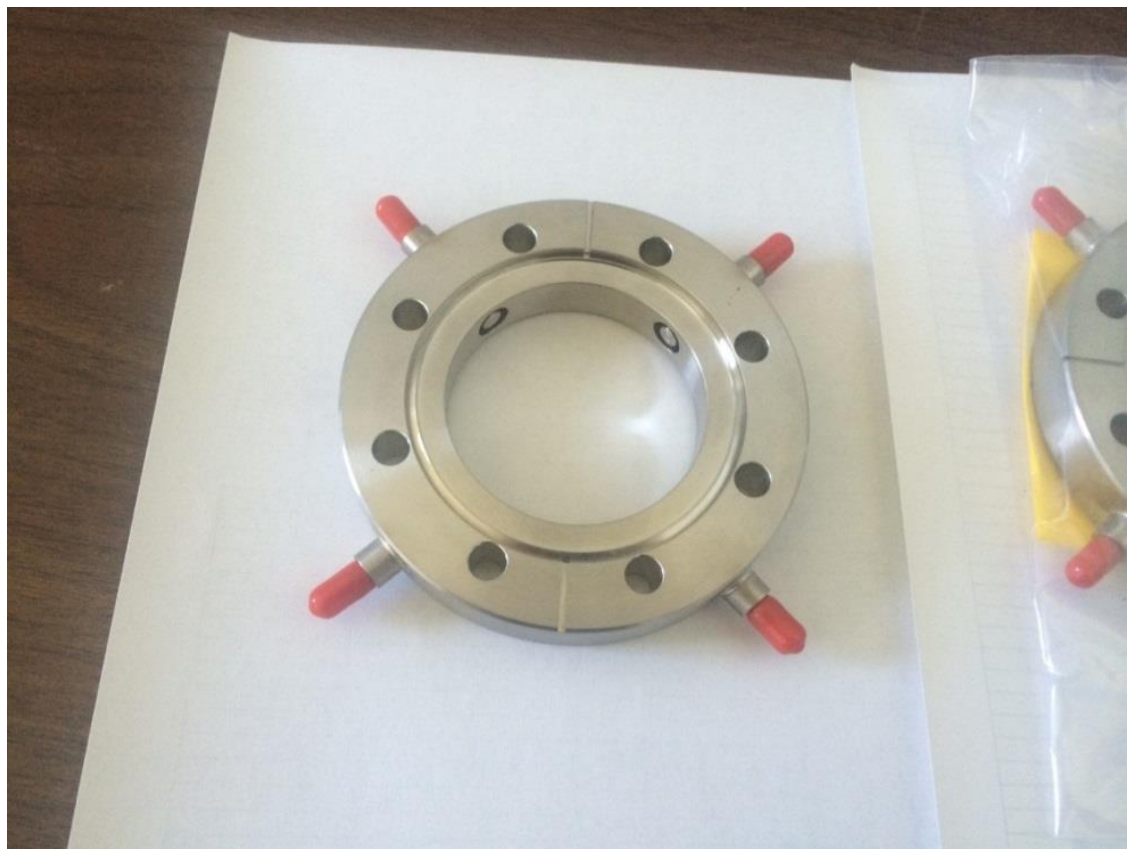

FIGURE 7 Pickup with Standard 4.5-in. CF Flanges Provided by LANL

position (Figure 8). In this setup, the beam displacement is calculated according to the following equations:

$$
\begin{aligned}
& \mathrm{dX}=\mathrm{Kx} \cdot(\log (\mathrm{U} 1 / \mathrm{U} 2)-\log (\mathrm{U} 3 / \mathrm{U} 4)) \cos \left(45^{\circ}\right) \\
& \mathrm{dY}=\mathrm{Ky} \bullet(\log (\mathrm{U} 1 / \mathrm{U} 2)+\log (\mathrm{U} 3 / \mathrm{U} 4)) \sin \left(45^{\circ}\right)
\end{aligned}
$$

The signal cable is a radio-frequency $(\mathrm{RF})$ cable with low damping in the RF range. Since the signals on each channel are processed independently but triggered synchronously, the cables' electrical length must be equal within $\pm 20 \mathrm{~cm}( \pm 1 \mathrm{~ns}$ delay).

The BPM electronic module S-BPM-111.3.2 is designed and manufactured by BERGOZ Instrumentation (http://www.bergoz.com). These modules operate in "SampleHold Mode" with signal processing time about $400 \mathrm{~ns}$. The processed signal can be displayed by an oscilloscope or post-processed by a slow gate-current integrator. The S-BPM module sets up the trigger signal just after processing the signal for the external ADC (analog-to-digital convertor). The chassis containing the S-BPM modules, power supply, and fan panel is mounted in a metal rack to protect it from possible RF noise (Figure 9).

The system was tested with the accelerator up to a $35 \mathrm{MeV}$ beam with length of $5.5 \mu \mathrm{s}$. The amplitude of the signal was about $0.5 \mathrm{~V}$ per $6 \mathrm{~mm}$ of beam displacement from the center of the pickup. Noise levels of the processed signal did not exceed $0.005 \mathrm{~V}$ (Figure 10). 


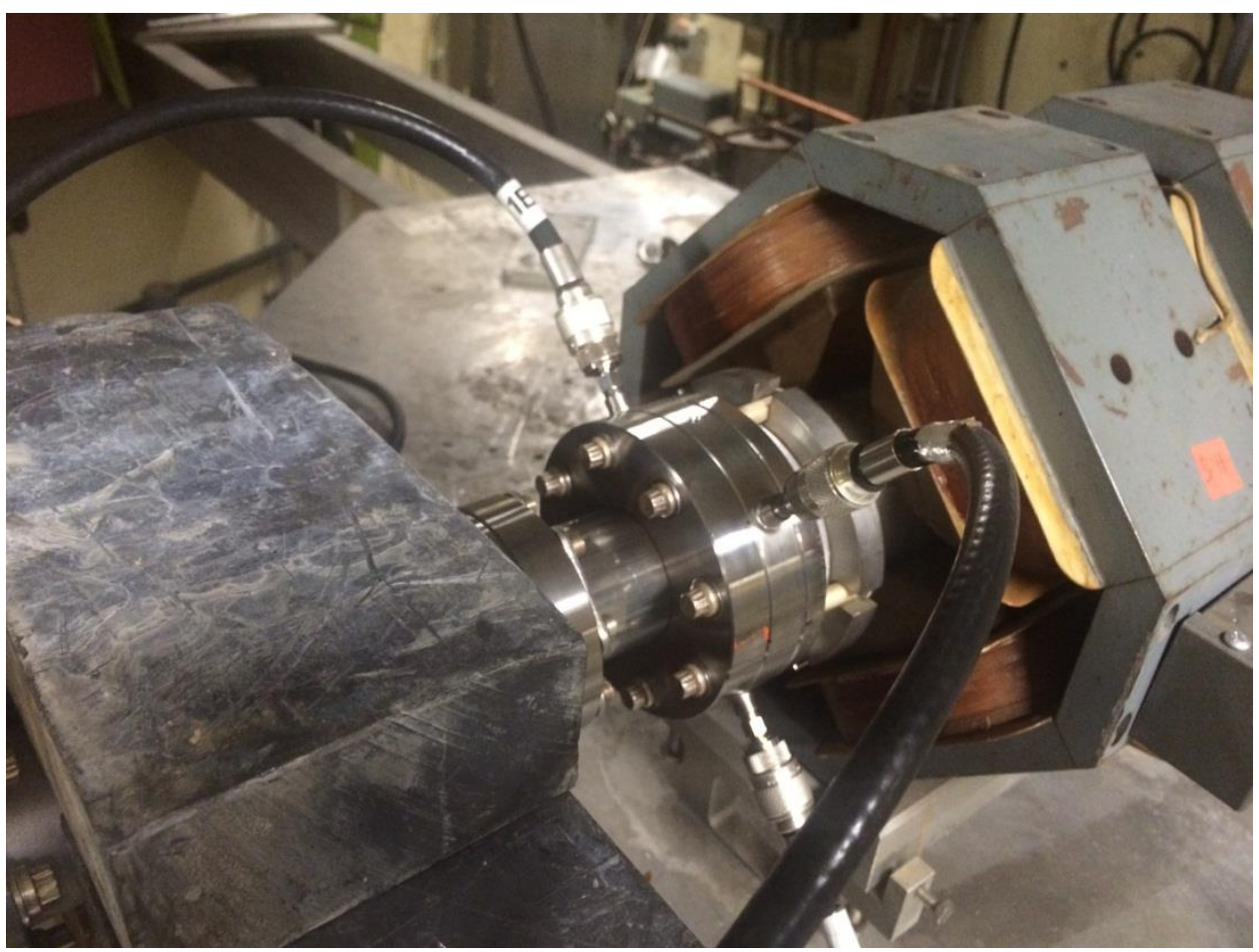

FIGURE 8 Pickup Installed at the Beam Transport Channel and Hooked Up with Signal Cables

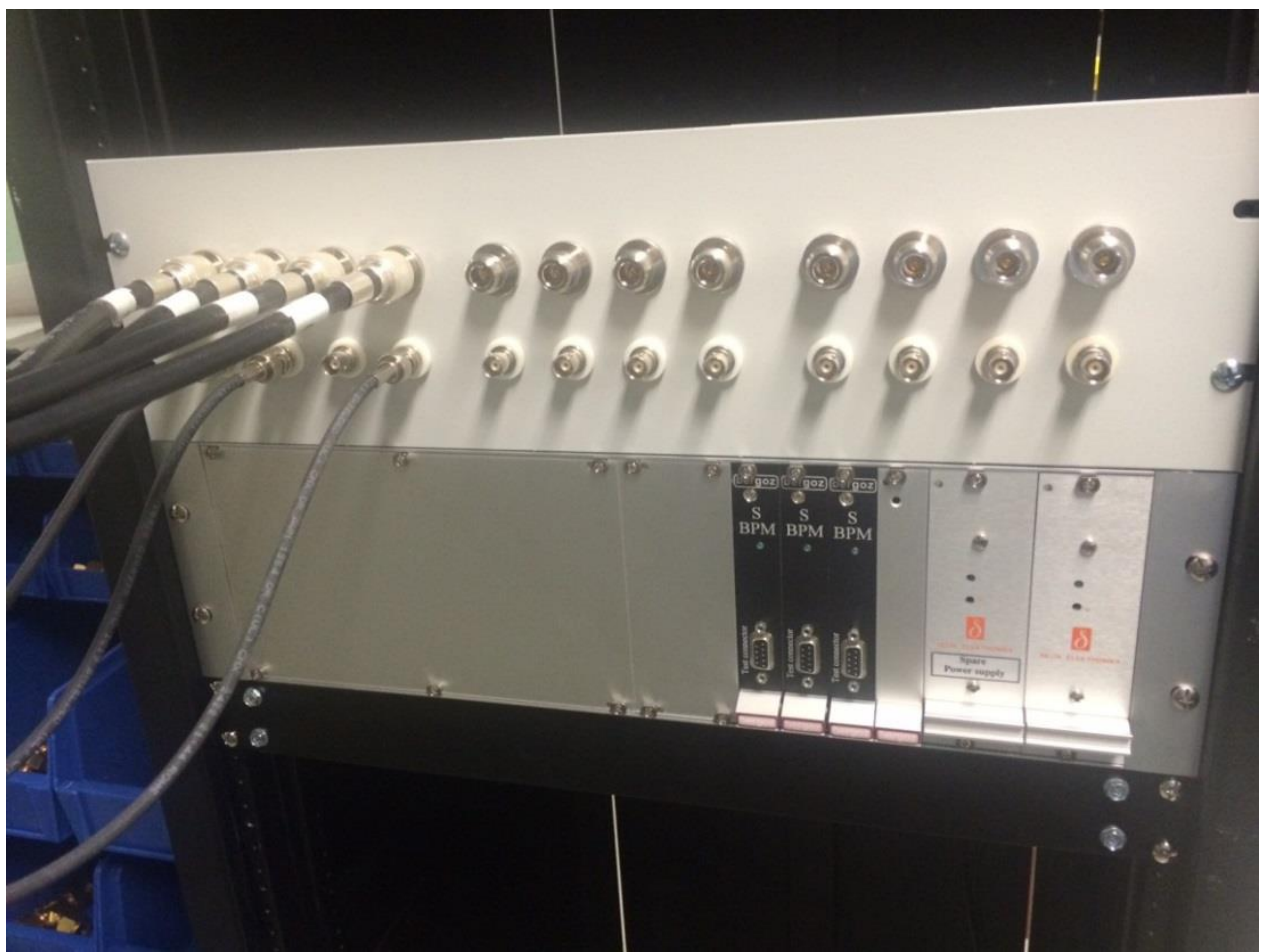

FIGURE 9 BPM's Control Electronics Installed in 19 in. Standard Rack (front view) 


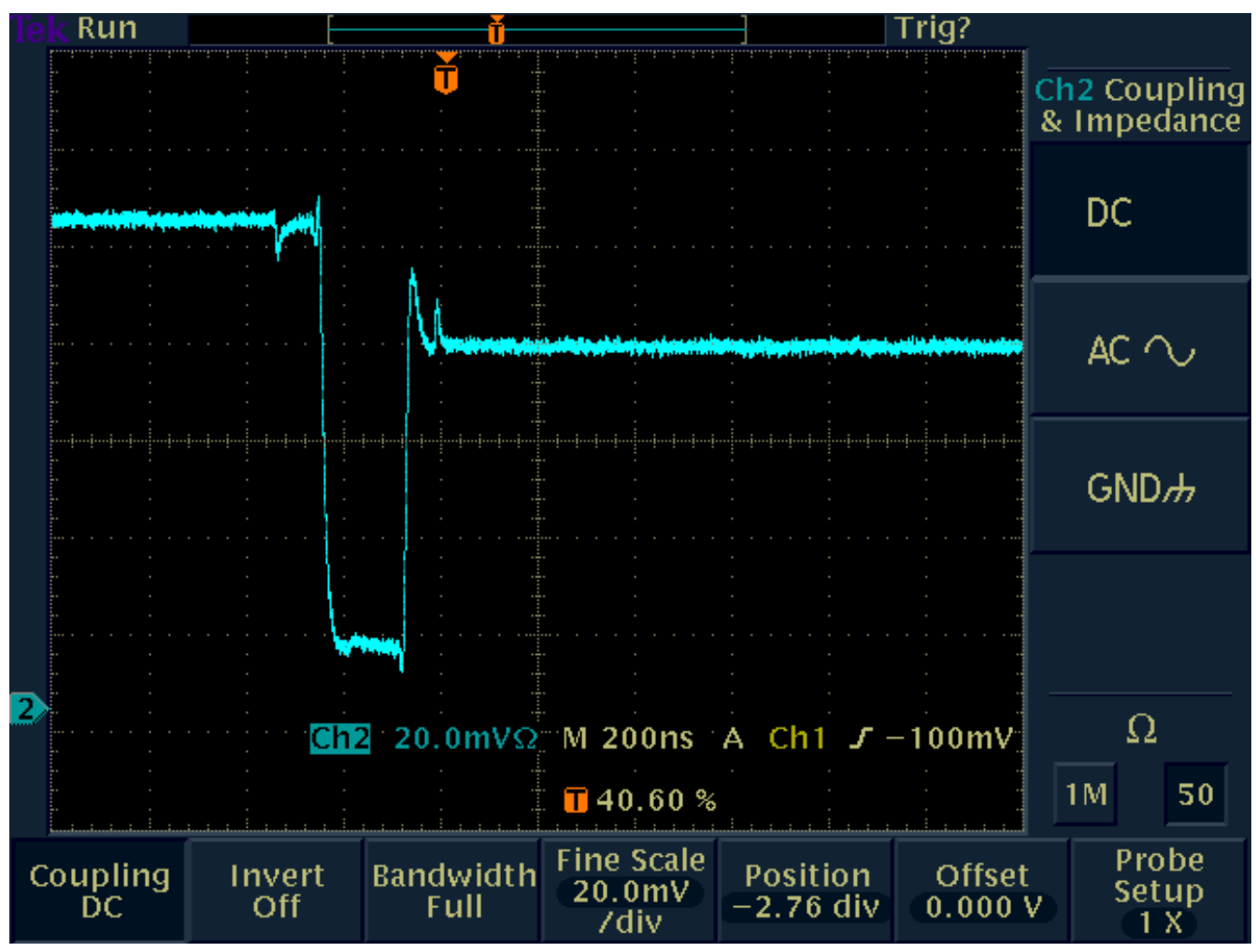

FIGURE 10 BPM Output Signal 


\section{CONCLUSION}

We have designed and tested several subsystems, including a beam collimator, beam stop, and BPM. For destructive (intercepting) elements, the high beam power of the proposed production facility accelerators represents a significant challenge. We have developed several production facility-scale conceptual designs that will be tested next year. We have continued radiation stability testing of the OTR and IR cameras at the VDG accelerator and will continue testing of those systems during irradiations at the Argonne linac facility utilizing X-ray and neutron dosimeters to correlate camera failures with doses. Further developments of the subsystems will provide information crucial for the design of a robust production facility.

\section{Reference}

1. Roman Gromov and Sergey Chemerisov, "Beam Transport Testing for the Production Accelerator Arrangement," ANL/CSE-13/39, Argonne National Laboratory (2013). 
This page intentionally left blank 


\section{APPENDIX A:}

10-MAGNET BEAM LINE FOR THE Mo-99 PRODUCTION FACILITY 
This page intentionally left blank 


\section{APPENDIX A:}

\section{0ํMAGNET BEAM LINE FOR THE Mo-99 PRODUCTION FACILITY}

\section{A.1 INTRODUCTION}

The beam-transport system is designed to deliver an electron beam from the accelerating structures to the target area. The design of the beam line depends on beam parameters (energy, energy spread, transverse profile, etc.) and target geometry. Elements of the beam-transport system should provide transporting, focusing, and diagnostics of the beam. Our choice for the transport system elements includes a 10-degree bending magnet, quadrupole FODO (focusingdefocusing) doublet, raster magnet, vacuum chambers, pump station, beam current monitor, and beam position monitor based on an OTR camera. Figure A.1 is a schematic of the configuration, where the main components of the transport channel for Mo-99 production line are:

1. Quadrupole Lenses (FODO and compensating magnet)

2. Raster Magnet

3. 10-degree Bending Magnet

4. Vacuum Chamber

5. Regular Vacuum Valve

6. Fast Acting Vacuum Valve

7. Beam Current Monitor

8. Beam Position Monitor (Optical Transition Radiation)

9. Fine Vacuum Sensor

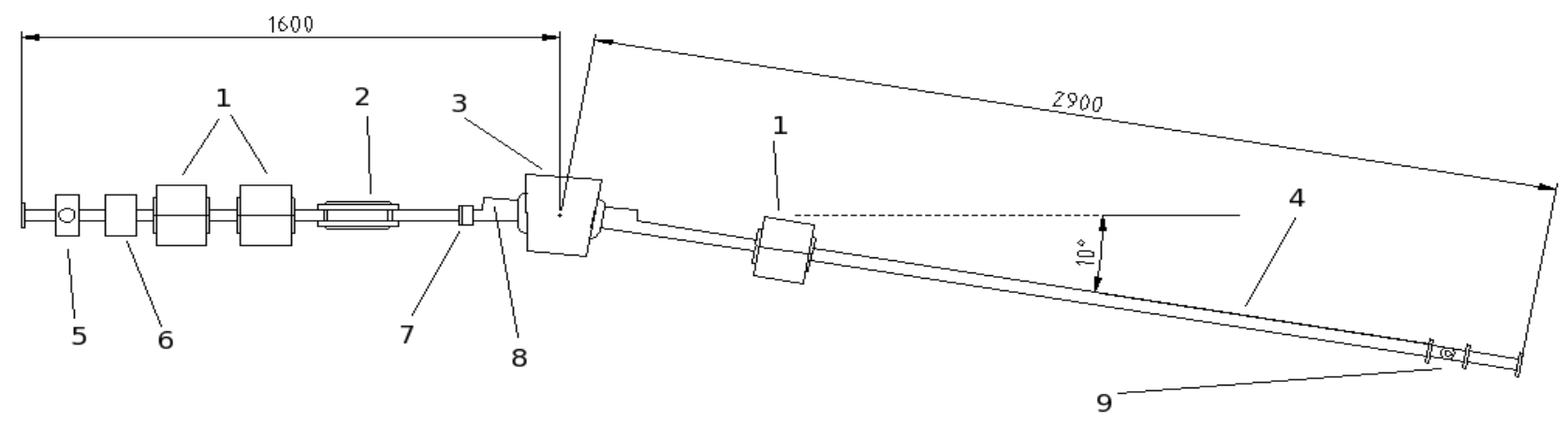

FIGURE A.1 Proposed Layout of Beam Transport System 
The channel optics is simulated by the MAD-X code (http://madx.web.cern.ch/madx/-Methodical Accelerator Design). The plots with simulations of the beam transverse dimensions are shown in Figure A.2.

The dispersion is small enough to provide the required beam size even with an energy spread of $\sim 3 \%$. A raster magnet is used to raster the beam onto the whole target surface and correct its trajectory. We have used the following set of beam parameters in our calculations:

- Initial beam diameter - $5 \mathrm{~mm}$

- Beam diameter on the target $-10 \mathrm{~mm}$

- Beam divergence $-0.5 \mathrm{mrad}$

- Beam energy - $34 \mathrm{MeV}$

- $\quad$ Energy spread - 3\% (1 MeV)

- Beam power-90-120 kW

The control system for the beam transport line should be incorporated into the linac control system.

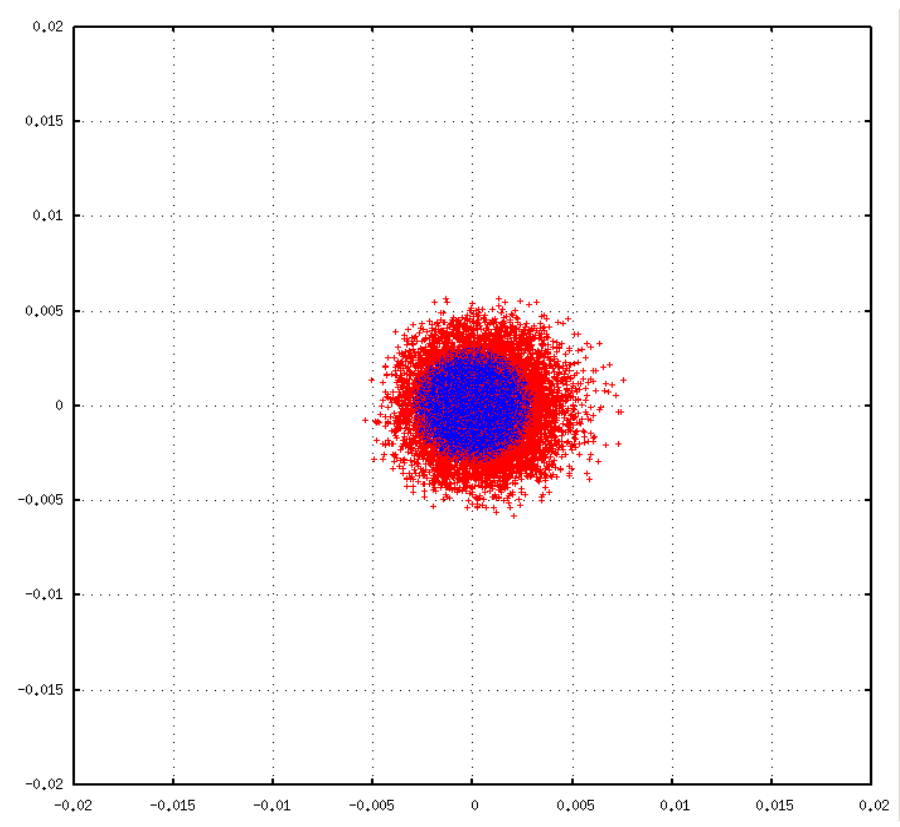

FIGURE A.2 Initial Beam Profile (blue) and Subsequent Beam Profile on the Target (red) 
To compensate for dispersion in the bending magnet, an additional quadrupole lens was installed after the bending magnet. The beam transverse size is relatively small and does not exceed $20 \mathrm{~mm}$ in the horizontal plane and $10 \mathrm{~mm}$ in the vertical plane. The vacuum chamber diameter is $40 \mathrm{~mm}$ before the bending magnet and $50 \mathrm{~mm}$ after it. Beam size in the raster magnet is about $8 \mathrm{~mm}$ in the vertical plane and $4 \mathrm{~mm}$ in the horizontal plane (Figure A.3).

\section{A.2 QUADRUPOLE LENSES}

Quadrupole lenses (QL) are used to focus an electron beam on the Mo target. Since the total length of the transport line is short, only one FODO doublet is necessary to focus the electron beam up to the required size. A good example of a QL that can be used in the proposed transport system is EMQD-01-163-394 from RadiaBeam Tech (www.radiabeam.com). Each quadrupole has the following parameters:

- Magnetic length $-16 \mathrm{~cm}$

- Aperture $-4.2 \mathrm{~cm}$

- Field gradient $-12.8 \mathrm{~T} / \mathrm{m}$

- Current-9.2 A

- Resistance per coil $-0.35 \mathrm{ohm}$

- Number of turns per coil - 251

- Total voltage $-13 \mathrm{~V}$

- Total power $-120 \mathrm{~W}(\mathrm{t})$

- Estimated price - $\$ 5,495$ (January, 2013)
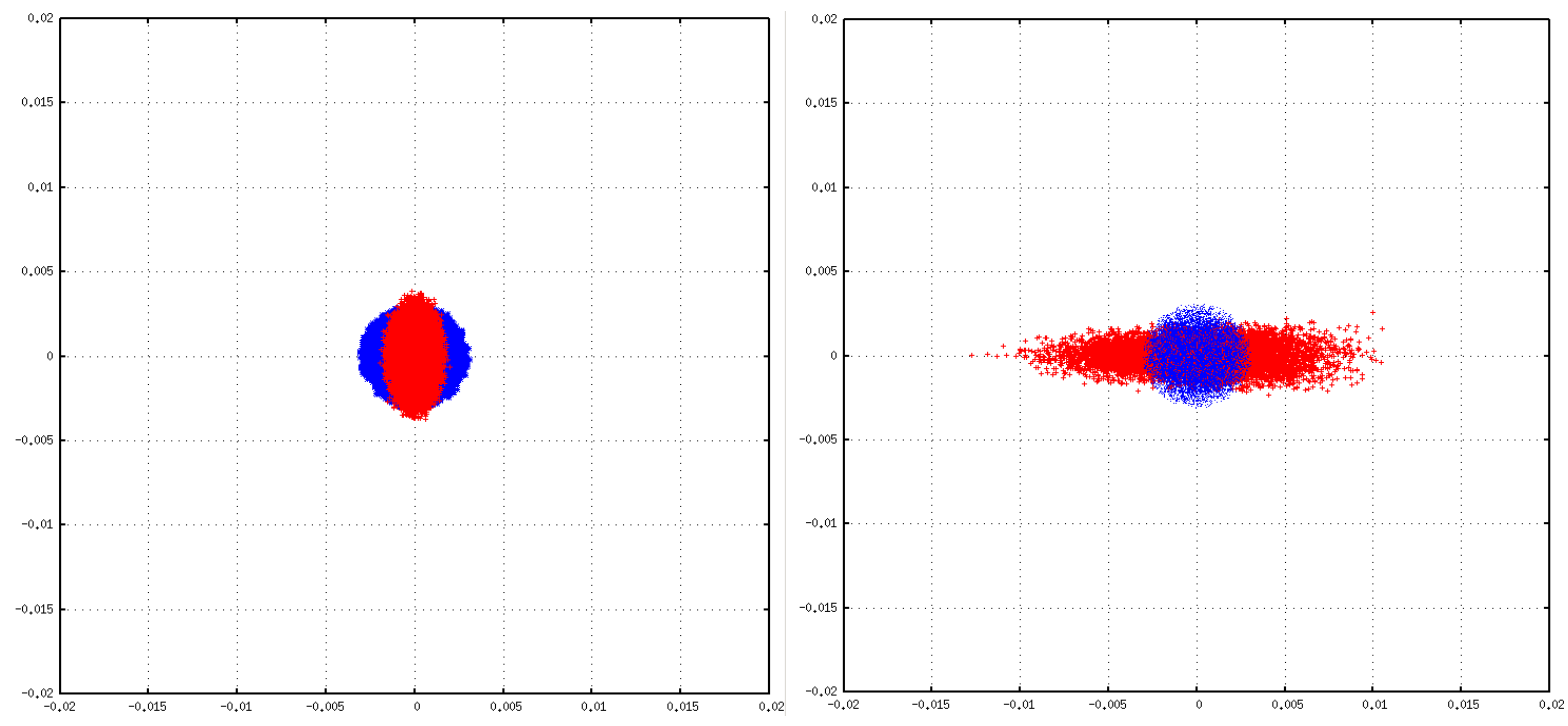

FIGURE A.3 Beam Transverse Profile in Raster Magnet (left) and Before Third Quadrupole (right) 


\section{A.3 RASTER MAGNET}

The main goal of the raster magnet (RM) is to evenly distribute an electron beam into the Mo target that has a larger diameter than the beam. To provide this, the RM should oscillate the magnetic field strength to move the beam over the target surface. Therefore, the RM should not have a yoke to avoid hysteresis. Raster-magnet geometry was designed to have magnetic field uniformity in the beam area (Figure A.4). The magnetic field deviation is less than $1.5 \%$ around $1 \mathrm{~cm}$ of the reference trajectory. Parameters for the raster magnet are:

- Distance from the target $-3.5 \mathrm{~m}$

- Maximum beam displacement from the target center $-14 \mathrm{~mm}^{1}$

- Bending angle -0.23 degrees $^{1}$

- Magnetic field strength - 45 Gs

- Number of coils -4

- Wire diameter $-1.5 \mathrm{~mm}$

- Number of turns - 60

- Coil current - 6.9 A

- Vertical coils:

- Length - $20 \mathrm{~cm}$

- Resistance -0.69 ohm

- Voltage - $4.8 \mathrm{~V}$

- Power - $33 \mathrm{~W}(\mathrm{t})$

- Inductance - $12.9 \mathrm{mkHn}$

- Time constant - $18.7 \mathrm{mks}$

- Horizontal coils:

- Length - $24 \mathrm{~cm}$

- Resistance -0.78 ohm

- Voltage - $5.4 \mathrm{~V}$

- Power - $37 \mathrm{~W}(\mathrm{t})$

- Inductance - $15.0 \mathrm{mkHn}$

- Time constant - $19.2 \mathrm{mks}$

Figure A.5 is a schematic of the cross section of the raster magnet.

1 Reference particle displacement on the target is $6 \mathrm{~mm}$, plus $8 \mathrm{~mm}$ for beam position correction. 


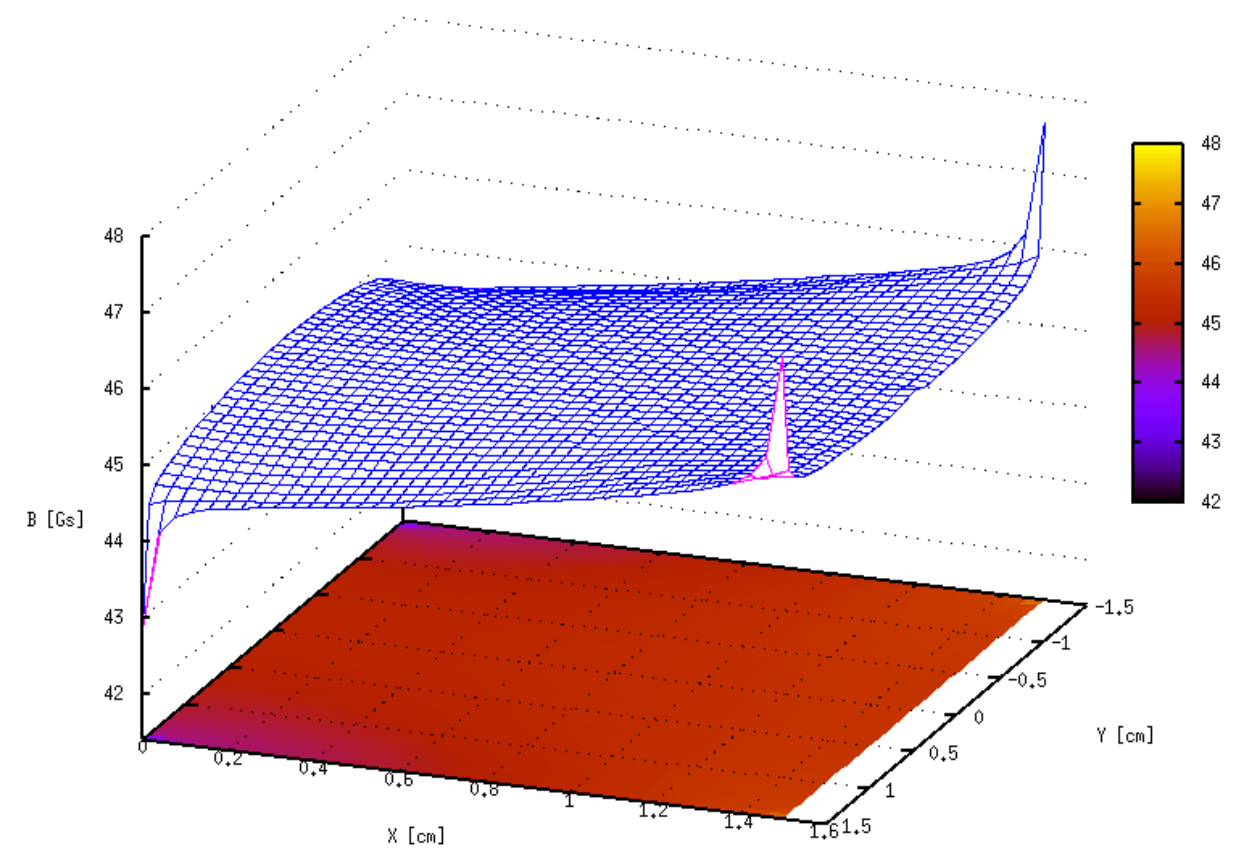

FIGURE A.4 Magnetic Field Strength Across Raster-Magnet Cross Section

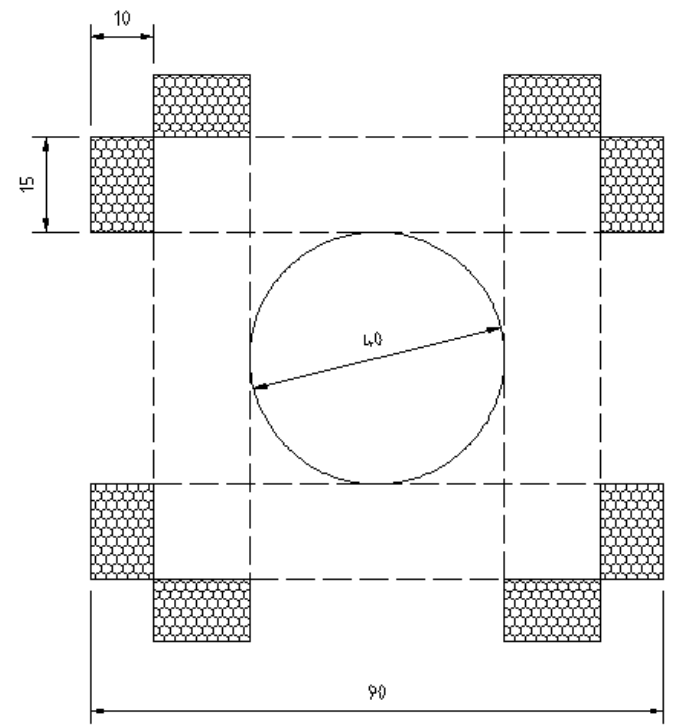

FIGURE A.5 Cross Section of the Raster Magnet 


\section{A.4 BENDING MAGNET}

The bending magnet (BM) is designed to bend a 34-MeV electron beam by 10 degrees. The main parameters are as follows:

- Total length $-20 \mathrm{~cm}$

- Bending angle - 10 degrees

- $\quad$ Magnetic field - 988 Gs

- Coils - 2 items

- Wire size -2 × $2 \mathrm{~mm}$

- Number of wings -216

- Coil current - 13.8 A

- Total coils resistance $-1.225 \mathrm{ohm}$

- Coils voltage $-17 \mathrm{~V}$

- Total power $-235 \mathrm{~W}(\mathrm{t})$

The BM does not require water cooling. Since the bending radius is small (10 degrees), the pole does not have to be curved to accommodate the beam trajectory; this make the magnet simpler to manufacture. The edges are perpendicular to the reference beam trajectory. Figures A.6 to A.8 describe the bending magnet.

\section{A.5 VACUUM SYSTEM}

Vacuum conditions for the beam channel are dependent on the requirements for beamquality delivery. Since the distance from the accelerator to the Mo target is short, the residual gas pressure should be about $10^{-6}$ Torr. Vacuum conditions depend on gas emission from vacuum chamber due to radiation:

$$
\mathrm{Q}=\mathrm{N} \cdot \mathrm{G} /\left(3.5 \cdot 10^{19}\right)
$$

where $\mathrm{Q}$ is gas emission incident by the synchrotron radiation ( $\bullet \cdot T o r r / s), N$ is number of photons leading the emission (photons/s), and $\mathrm{G}$ is the emission coefficient (mol/photon). Furthermore,

$$
\mathrm{N}=7 \cdot 10^{20} \cdot \mathrm{E} \cdot \mathrm{I}
$$

For regular performance, the emission coefficient $\mathrm{G}$ is about $10^{-5}[1]$. For $\mathrm{E}=0.038 \mathrm{GeV}$ and peak beam current $\mathrm{I}=0.3 \mathrm{~A}$, the gas emission $(\mathrm{Q})$ is expected to be $2.3 \times 10^{-5} \mathrm{~L} \cdot \mathrm{Tor} / \mathrm{s}$.

The effective pumping speed (S) is defined by the equation:

$$
\mathrm{S}=\mathrm{Q} / \mathrm{P}
$$

For pressure $\mathrm{P}=10^{-6}$ Torr, the pumping speed should be $\mathrm{S}=23 \mathrm{~L} / \mathrm{s}$. 


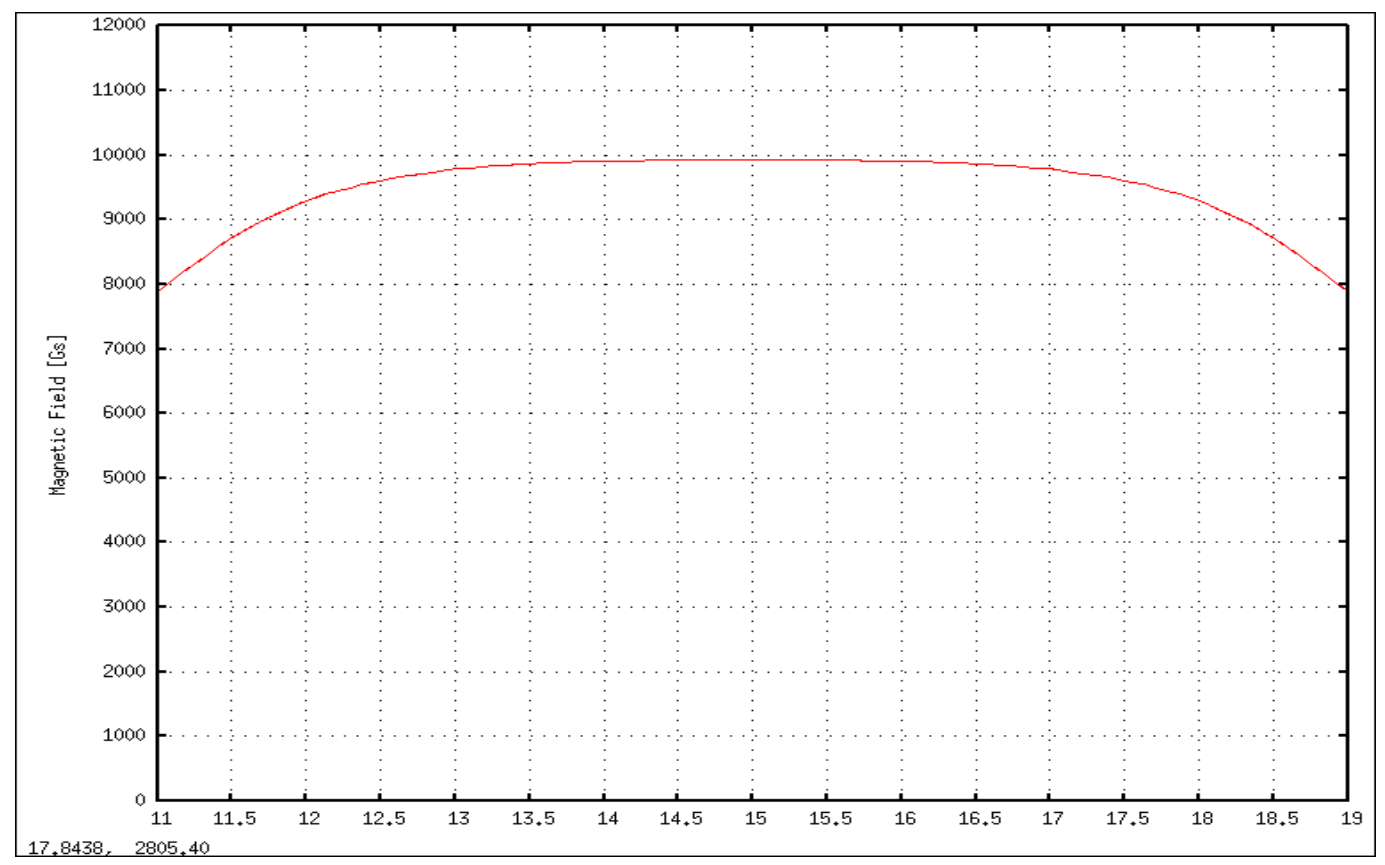

FIGURE A.6 Transverse Magnetic Field in the Pole Gap

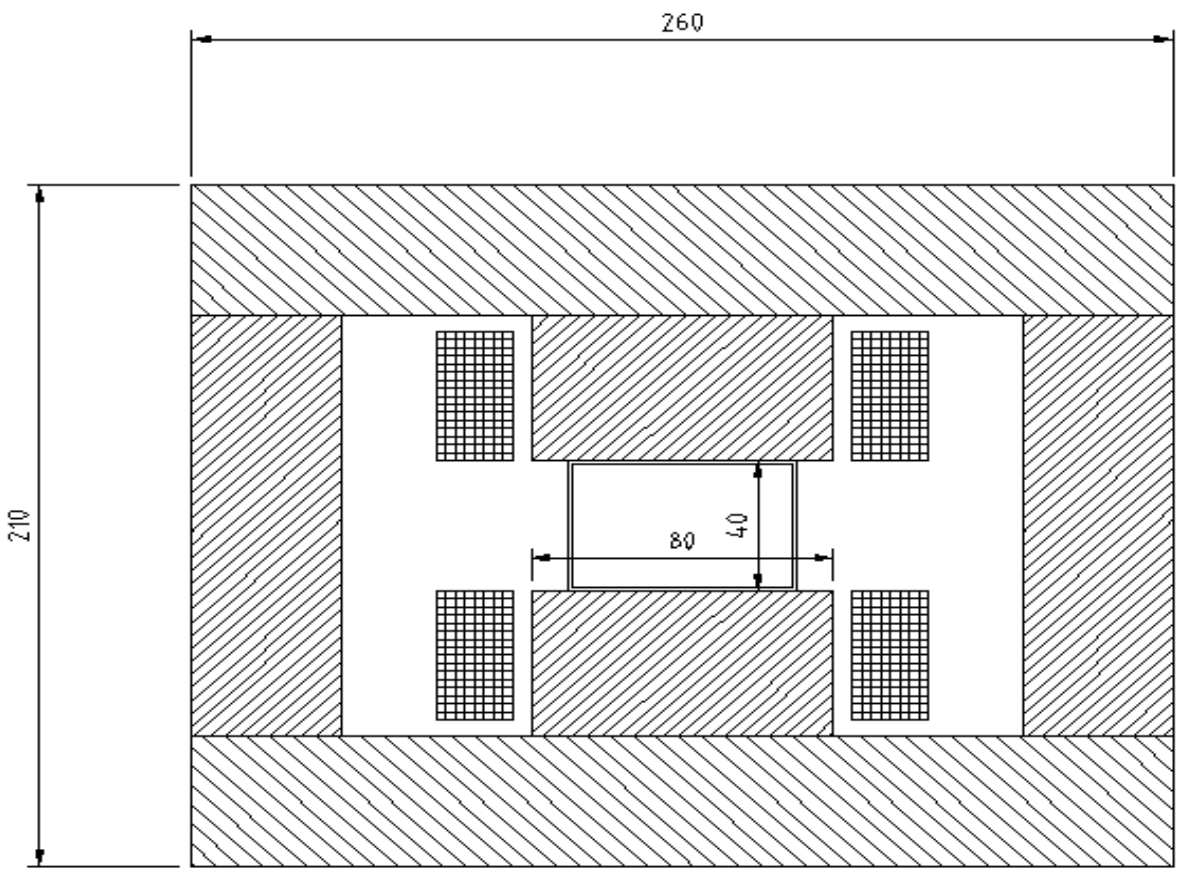

FIGURE A.7 Transverse Cross Section of Bending Magnet 


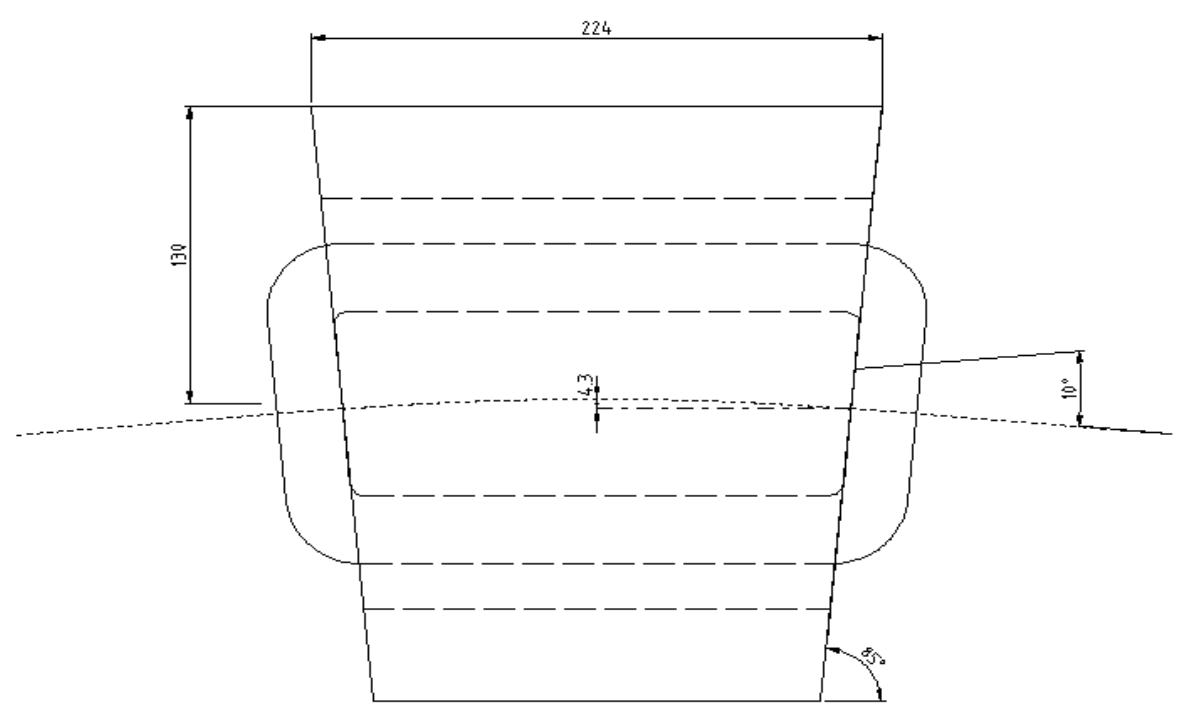

FIGURE A.8 Top View of Bending Magnet

Taking into account that the initial gas emission $(\mathrm{G})$ before conditioning of the vacuum chamber can be up to $10^{-4}$, the pumping speed should be higher. Using a 100-L/s pump station can provide the vacuum level of at least $4 \times 10^{-6}$ torr during the conditioning process. Figure A.9 is a schematic of the vacuum system.

\section{A.6 BEAM POSITION MONITORING}

The beam position is monitored by cameras. One line is used to control the beam spot at the target; another one is for beam position monitoring after acceleration structures. Mirrors are fabricated from polished water-cooled copper. Their surfaces are polished and covered by a thin gold layer. Figure A.10 is a schematic of the port set-up for beam position monitoring. 


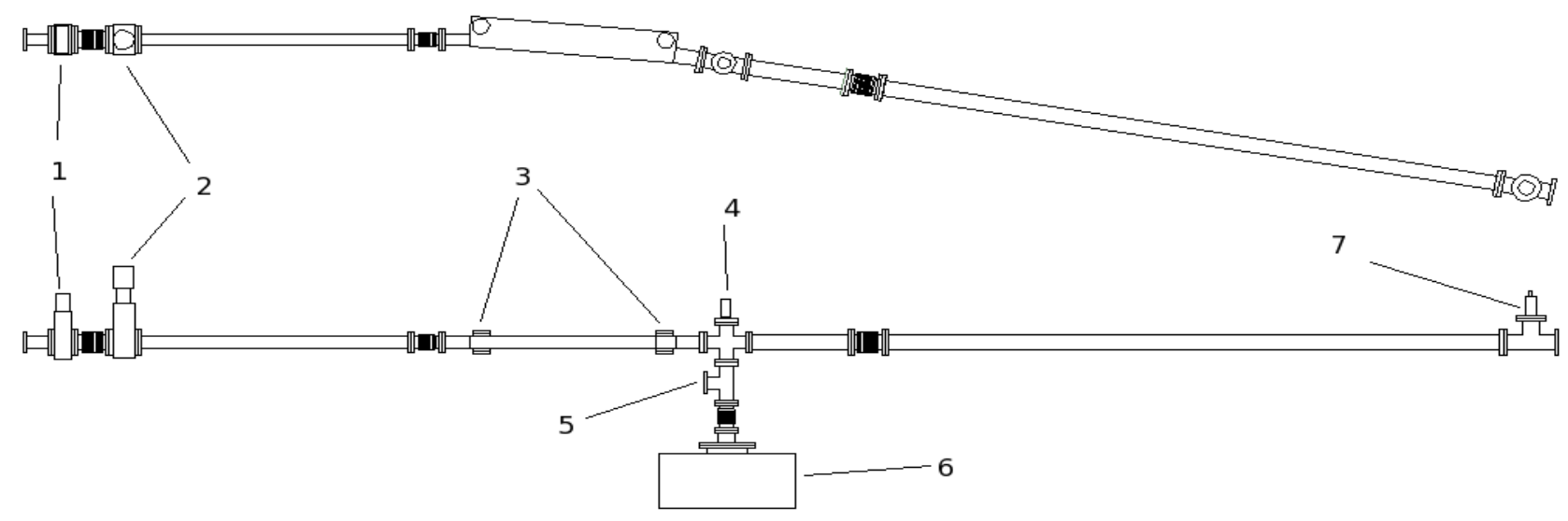

FIGURE A.9 Vacuum Chamber Elements

$1=$ Vacuum Valve

2 = Fast Acting Gate Valve (FAV)

3 = Beam Diagnostic Ports

$4=$ Vacuum Gauge
$5=$ Rough Pump Port

$6=$ Ion Pump

7 = Fine Vacuum Sensor (FVS) for FAV

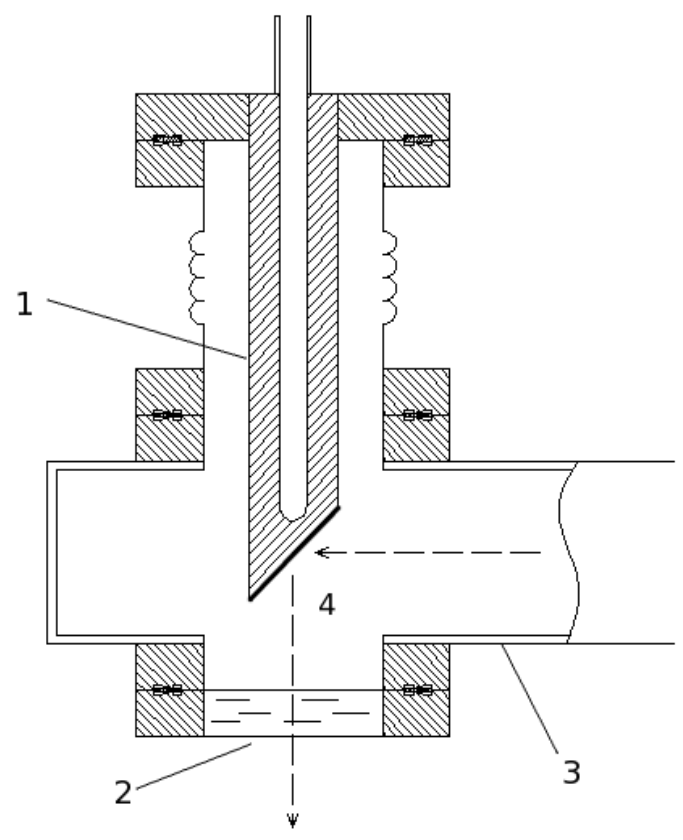

FIGURE A.10 Port Cross Section for Beam Position Monitoring

$$
\begin{aligned}
& 1=\text { Water-Cooled Copper Body } \\
& 2=\text { Crystal Mirror } \\
& 3=\text { Vacuum Chamber } \\
& 4=\text { Au-Covered Mirror }
\end{aligned}
$$




\section{A.7 FINE VACUUM SENSOR}

A fine vacuum sensor (FVS) should activate the FAV in case of a sudden increase in pressure. A FVS from VAT Vakuumventile AG (www.vatvalve.com, Product number 770SF99NN) can be used for this purpose. Its specifications are:

- Trigger pressure range $-1 \times 10^{-3}-1 \times 10^{-1} \mathrm{mbar}$

- Trigger time - $1 \mathrm{~ms}$

- Radiation resistance $-8 \mathrm{~Gy}\left(10^{10} \mathrm{rad}\right)$

- Max. bake-out temperature $-250^{\circ} \mathrm{C}$

- Mounting position - Any 


\section{APPENDIX B:}

ALPHA MAGNET BEAMLINE FOR THE Mo-99 PRODUCTION FACILITY 
This page intentionally left blank 


\section{APPENDIX B:}

\section{ALPHA MAGNET BEAMLINE FOR THE Mo-99 PRODUCTION FACILITY}

\section{B.1 BEAMLINE ANALYSIS FOR ALPHA MAGNET DESIGN}

This report describes the design of a beamline for delivering a beam from linac to a target in a facility configuration in which the target is illuminated from both sides by two parallel linacs. An alpha magnet, a non-dispersive element that bends the beam approximately $90^{\circ}$, is used to turn each beam toward the target. In this design, the beam is focused to a compact spot on the target, and a pair of steering magnets is used to raster the beam across the target. The goals for the design were simplicity, minimization of beam loss, and minimization of the number of magnets in the areas where they are most prone to radiation damage.

\section{B.2 SIMULATIONS}

Simulations were carried out primarily in Parmela, a particle tracking code developed at Los Alamos National Laboratory. An exception was made for the alpha magnet. Because Parmela, as well as most beam simulation codes are limited in the way they support bending elements, a different approach was required. Therefore, the beam distribution was exported from Parmela at the entrance of the alpha magnet, the effect of the alpha magnet was applied, and the beam was then imported back into Parmela [1]. Transport through the alpha magnet was modeled by applying matrix transformations to the third order, an approach developed by Borland [2]. Because of the beam energy, space-charge interactions are negligible, so this method is expected to produce a high degree of accuracy.

Because the beam distribution at the exit of the linac is partially, but not completely, known, simulations were conducted for a range of initial conditions. In all cases, the beam energy is expected to be centered near $42 \mathrm{MeV}$, and the initial spot size is expected to be 3-mm full-width at half maximum (FWHM). We assumed Gaussian spatial and momentum distributions except for the longitudinal spatial distribution, which is assumed to be uniform. In the case of the transverse spatial distributions, the 3-mm FWHM corresponds to a Gaussian distribution with a standard deviation of $\sigma=1.27 \mathrm{~mm}$. The transverse spatial distributions were terminated at $3 \sigma$. The transverse-momentum distributions can be determined from the beam quality (emittance), which had not been precisely specified. Therefore, we studied three values for the emittance: $9 \mu \mathrm{m}, 50 \mu \mathrm{m}$, and $100 \mu \mathrm{m}$. [We refer here to the normalized, $4 \times \mathrm{RMS}$ (root mean square) emittance.] We believe the actual value can be reasonably expected to lie in the given range. For the longitudinal momentum distribution, we studied the cases of $2 \sigma=3 \%, 5 \%$, and $10 \%$ of the nominal beam momentum. We assume the bunch length is $10^{\circ}$ of the radiofrequency $(\mathrm{RF})$ phase, where the RF frequency is $2.86 \mathrm{GHz}$. The results do not depend strongly on the longitudinal spatial distribution. 


\section{B.3 BEAMLINE DESIGN}

The beamline has been designed around the properties of the alpha magnet. This approach is required because the alpha magnet has focusing properties in the transverse planes that depend on the beam properties in a more complicated way than the standard focusing elements. The essential characteristic of the design is that the beam expands at the exit of the linac, is modified as it passes through the alpha magnet, and is finally focused to a spot on the target by a quadrupole doublet. The alpha magnet also compresses or expands (in this case, expands) the length of the beam. For this application, the bunch length is not a critical parameter.

In the $9-\mu \mathrm{m}$ and $50-\mu \mathrm{m}$ cases, a single quadrupole doublet was sufficient to focus the beam onto the target. For the $100-\mu \mathrm{m}$ case, an additional quadrupole was required to compensate for the focusing effects of the alpha magnet. This magnet was positioned between the linac and the alpha magnet. In addition to the focusing elements, three sets of dipole magnets were required. The first two sets are used to correct the alignment and angle of the beam at the entrance of the alpha magnet. The last pair is used to raster the beam across the sample. A minimum length of drift space was required so that the desired beam profile at the sample could be achieved at the desired distance from the target (as determined by the requirement for shielding). This space was incorporated before the alpha magnet. It is possible that this distance could be reduced by adapting the focusing incorporated into the linac. However, the details of the focusing through the linac are not known at this point. A schematic of the beamline for the $9-\mu \mathrm{m}$ and $50-\mu \mathrm{m}$ cases is shown in Figure B.1.

For each combination of emittance and energy spread, it was found that all of the beam charge could be transported to the target with a beam pipe not exceeding 2 -in. inner diameter. This condition has been achieved for the assumed Gaussian spatial and momentum distributions. However, it does not account for particles that may lie outside the core of the beam (halo). By definition, these particles are expected to constitute a small fraction of the beam. Once the beam from the linac has been experimentally characterized, it will be possible to obtain updated

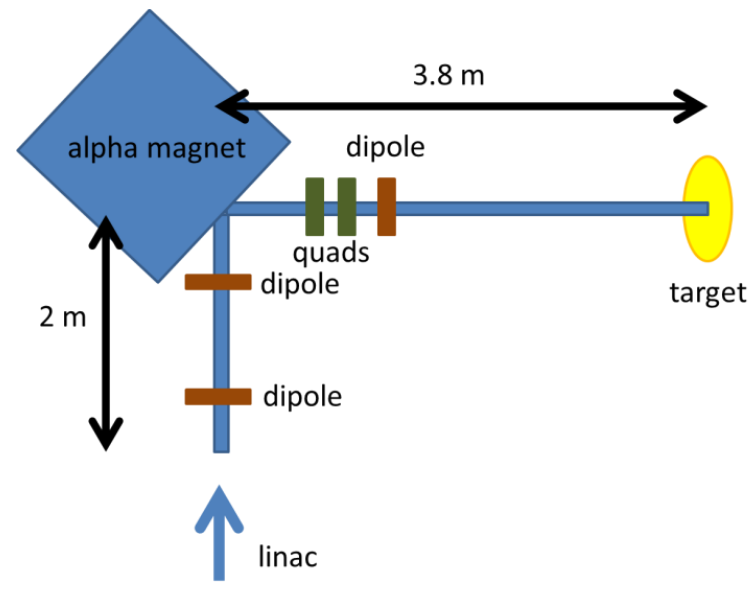

FIGURE B.1 Schematic Representation of the Beamline for the 9- $\mu \mathrm{m}$ and $50-\mu \mathrm{m}$ Cases 
results. The beam profile for a representative case (emittance $=50 \mu \mathrm{m}$, energy spread $= \pm 5 \%$ ) is shown in Figure B.2.

The spot size at the target location for each combination of emittance and energy spread is illustrated in Figure B.3.

\section{B.4 DESIGN OF THE ALPHA MAGNET}

An alpha magnet, in the most typical form, is characterized by a linearly increasing field in the plane of the beam's trajectory [3]. A particle entering the field at $\alpha=40.7^{\circ}$ relative to the center axis of the magnet exits the magnet at $-40.7^{\circ}$ with no dependence on the particle's energy. This contrasts with most bending magnets, which are dispersive in proportion to the bend angle. The alpha magnet allows a beam with a large energy spread to be bent approximately $90^{\circ}$ with minimal dispersion.

The dimensions required for the alpha magnet are determined by the beam energy higher beam energy corresponds to a larger orbit. The maximum depth the electron reaches in the magnet is given by the equation [3]:

$$
d=\sqrt{\frac{2 \beta \gamma m c}{e g}(1+\sin \alpha)}
$$

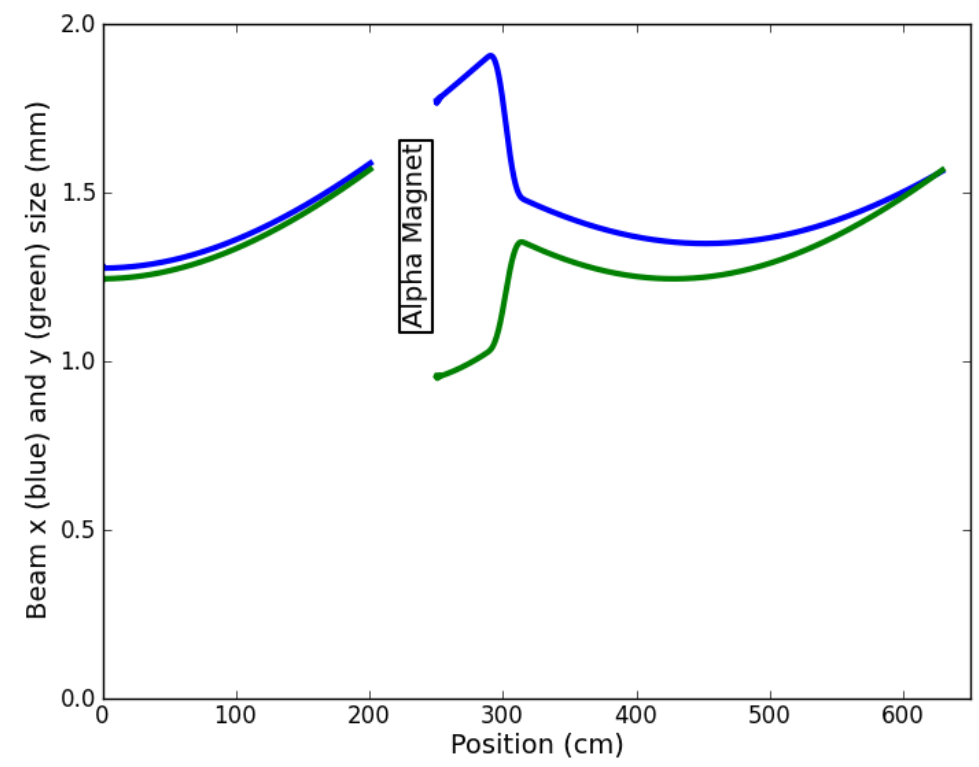

FIGURE B.2 Beam Profile for the Case with 50- $\mu \mathrm{m}$ Emittance and $\pm 5 \%$ Energy Spread. As described in the text, the electron trajectories are not tracked in detail through the alpha magnet. 

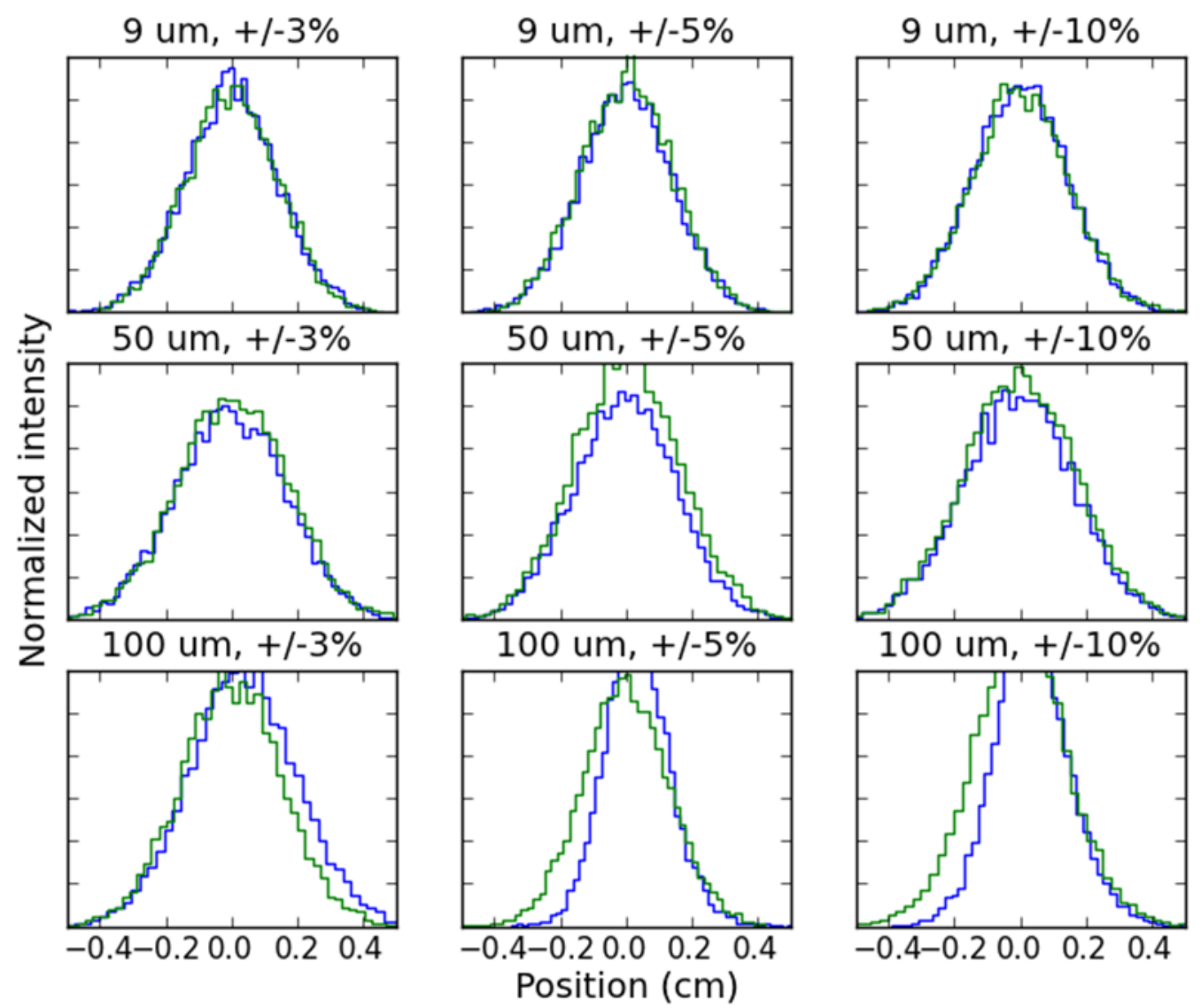

\section{FIGURE B.3 Spot Size on Target in $x$ (blue) and $y$ (green) Directions for Each Combination of Emittance and Energy Spread Considered. In each case, the FWHM bunch size is less than 5 mm.}

where $\mathrm{m}$ is the electron rest mass, $\mathrm{c}$ is the speed of light, $\mathrm{e}$ is the elementary charge, and $\mathrm{g}$ is the field gradient. The term $\beta \gamma \mathrm{mc}$ represents the momentum of the electrons. Normal conducting magnets can produce maximum fields of approximately $1 \mathrm{~T}$; in other words, in terms of the variables defined above, $d g \leq 1 \mathrm{~T}$. It is desirable to make the gradient as large as possible to minimize the size of the device. Taking $\mathrm{d} g=1 \mathrm{~T}$, the equation above becomes

$$
\sqrt{\frac{2 \beta \gamma m c g}{e}(1+\sin \alpha)}=1 \mathrm{~T}
$$

The design energy for the linac is $42 \mathrm{MeV}$. To leave a margin for uncertainty, we take $\mathrm{E}=45 \mathrm{MeV}$, which corresponds to $\beta \gamma \approx 90$. With $\alpha=40.7^{\circ}$, solving the equation yields $g=2.0 \mathrm{~T} / \mathrm{m}$. With this value for the gradient, $d=0.5 \mathrm{~m}$. The relationship between the width and depth of the orbit, w/d $=0.6$, can be calculated numerically by using the scaling relationships for the alpha magnet [2]. Given this relationship, the width of the trajectory is $w=0.3 \mathrm{~m}$. 
A preliminary alpha magnet design was explored by using the magnetostatic code Poisson. Poisson [1] is a two-dimensional code, which is acceptable for this application because the field is designed to be uniform across the width of the magnet. The magnet must be made wide enough so that the electron trajectories are confined to the uniform region of the field. This design is shown in Figure B.4.

\section{B.5 ALIGNMENT REQUIREMENTS FOR THE ALPHA MAGNET}

Misalignments of any bending or focusing elements in a beamline adversely affect beam quality. For an alpha magnet, the quantitative relationships that relate specific misalignments to their effect on the beam are more complex than for typical beamline elements. To understand these relationships, we carried out calculations by using the transport matrices described above. For various misalignments in position and angle, we compared the contributions of the secondand third-order matrix elements to the linear terms. Because the higher order terms couple the various spatial and angular errors, it is necessary to consider all possible combinations of misalignments. It was found that position misalignments up to $\pm 5 \mathrm{~mm}$ in either the horizontal or vertical orientation are not problematic. The most sensitive relationship is the effect of misalignments in the vertical angle $\left(\mathrm{y}^{\prime}\right)$ on the horizontal angular distribution $\left(\mathrm{x}^{\prime}\right)$. This relationship is illustrated quantitatively in Figure B.5. Because of the simplicity of the beamline, it will be possible to optimize the alignment by steering the beam at the entrance of the alpha magnet while observing the beam spot at the target.

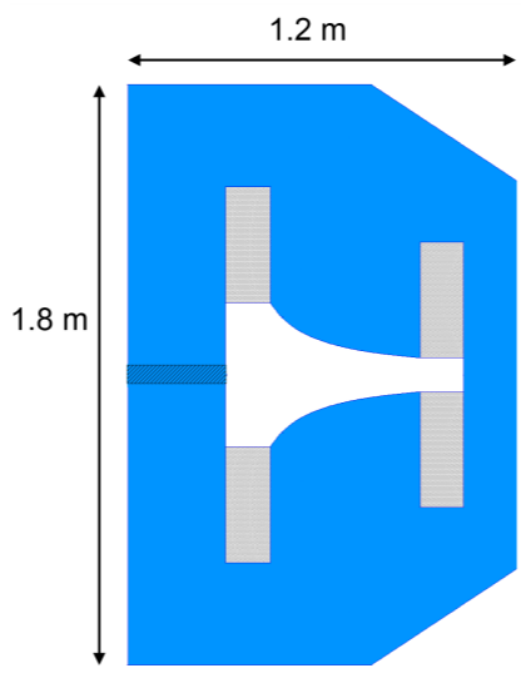

FIGURE B.4 Preliminary Design for the Alpha Magnet Cross Section. The blue region is iron, the grey areas are coils, and the white area is vacuum. Electrons enter and exit through penetrations in the front surface (dark blue). The electron orbits lay on-axis in the plane perpendicular to the cross section. 


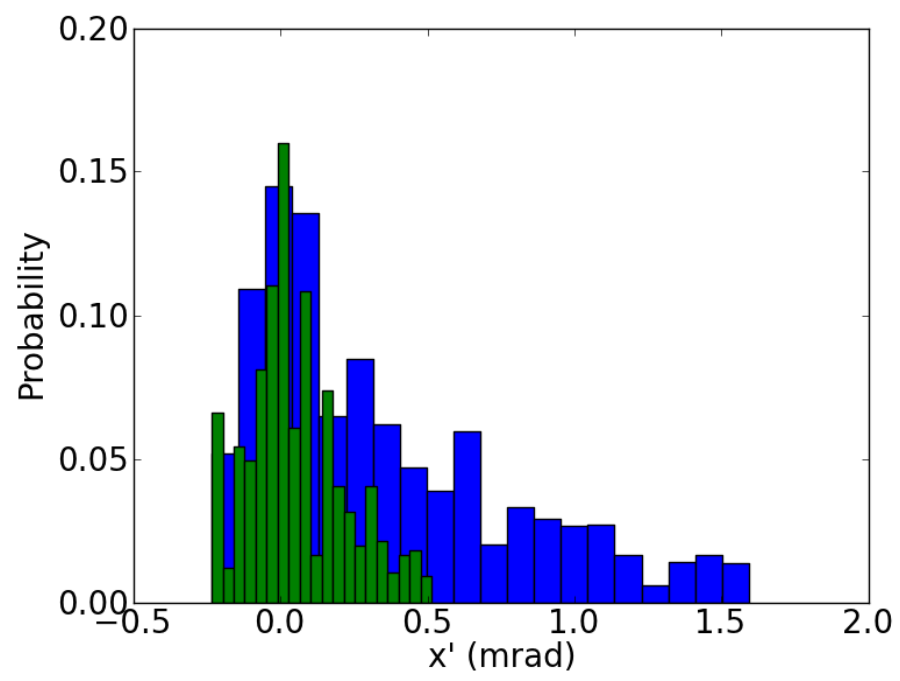

FIGURE B.5 Probability for a Given Cumulative Higher Order Contribution to $\mathrm{x}^{\prime}$ for Two Ranges of $y^{\prime}$. Position offsets are spread evenly over the range $\pm \mathbf{5 m}$ in both $x$ and $y$. Initial values for $x^{\prime}$ are spread over \pm 5 mrad. Initial values for $y^{\prime}$ are spread over \pm 2.5 (green) or \pm 5 mrad (blue). The dependence of misalignments in $y^{\prime}$ on the $x^{\prime}$ distribution illustrated here was determined to be the most critical alignment consideration.

\section{References}

1. Los Alamos National Laboratory, "Parmela and Poisson, http://laacg.lanl.gov/laacg/services/ serv_codes.phtml, accessed December 2014.

2. Michael Borland, "A High-Brightness Thermionic Microwave Electron Gun," Ph.D. dissertation, Stanford University (1991).

3. Harald A. Enge, "Achromatic Magnetic Mirror for Ion Beams," Rev. Sci. Instrum. 34, 385 (1963). 


\section{APPENDIX C:}

PRELIMINARY HEAT TRANSFER ANALYSIS 
This page intentionally left blank 


\section{APPENDIX C:}

\section{PRELIMINARY HEAT TRANSFER ANALYSIS}

Preliminary heat transfer analysis for the Mo99 Collimator

$\mathrm{e}_{\mathrm{abx}}:=5.4 \cdot 1 \cdot 6 \cdot 10^{-13} \frac{\mathrm{J}}{\mathrm{cm}} \quad$ Electron energy absorbed per unit length along the beam

$e_{a b t}:=42 \cdot 1 \cdot 6 \cdot 10^{-13} \mathrm{~J} \quad$ Total electron energy absorbed

$\mathrm{Ab}_{\text {factor }}:=0.8 \quad$ Conversion factor from electronenergy to heat

$q_{\text {beam }}:=120 \mathrm{~kW} \quad$ Total beam energy

$D_{\text {beam }}:=2.54 \mathrm{~cm} \quad$ Assumed beam diameter

$\mathrm{Ax}_{\text {beam }}:=\frac{\pi \cdot \mathrm{D}_{\text {beam }}{ }^{2}}{4}=5.067 \cdot \mathrm{cm}^{2} \quad$ Cross sectional area of beam

$q_{\text {tgenx }}=\frac{e_{a b x}}{e_{a b t}} \cdot A b_{\text {factor }} \cdot q_{\text {beam }}=12.343 \cdot \frac{\mathrm{kW}}{\mathrm{cm}} \quad \begin{aligned} & \text { Internal heat generation per unit } \\ & \text { length al ong the beam assuming a }\end{aligned}$ uniform beam profile

$q_{\text {gen }}:=\frac{q_{\text {tgenx }}}{\mathrm{Ax}_{\text {beam }}}=2.436 \cdot \frac{\mathrm{kW}}{\mathrm{cm}^{3}} \quad$ Uniform internal heat generation per unit volume

The model assumes a 1-D conduc tive heat transfer analysis with a uniform internal heat generation and a convective boundary condition at one end $(x=0)$ and an insulated boundary at the other $(x=L)$.

$$
\begin{aligned}
& \mathrm{T}_{\text {fluid }}:=20^{\circ} \mathrm{C} \quad \text { Average temperature of the coolant water } \\
& \mathrm{T}_{\text {smax }}:=100^{\circ} \mathrm{C} \quad \text { Maximum wall surface temperature to avoid boiling } \\
& \mathrm{h}_{\text {conv }}:=2 \frac{\mathrm{W}}{\mathrm{cm}^{2} \cdot \mathrm{K}} \quad \text { Reasonable maximum convective heat transfer coefficient for water } \\
& \mathrm{L}_{\text {wall }}:=\frac{\mathrm{h}_{\text {conv }}}{\mathrm{q}_{\text {gen }}} \cdot\left(\mathrm{T}_{\text {smax }}-\mathrm{T}_{\text {fluid }}\right)=0.066 \mathrm{~cm} \quad \mathrm{~L}_{\text {wall }}=0.026 \text { in } \quad \begin{array}{l}
\text { Maximum allowable wall } \\
\text { thickness to avoid boiling }
\end{array} \\
& \mathrm{k}_{\mathrm{al}}:=2.16 \frac{\mathrm{W}}{\mathrm{cm} \cdot \mathrm{K}} \quad \text { Thermal conductivity of aluminum at ambient temperature } \\
& \mathrm{T}_{\mathrm{almax}}:=\frac{\mathrm{q}_{\mathrm{gen}} \cdot \mathrm{L}_{\mathrm{wall}}{ }^{2}}{2 \cdot \mathrm{k}_{\mathrm{al}}}+\mathrm{T}_{\mathrm{smax}}=102.433^{\circ} \mathrm{C} \quad \text { Maximum temperature of aluminum }
\end{aligned}
$$




$$
\begin{aligned}
& \mathrm{k}_{\mathrm{SS}}:=.15 \frac{\mathrm{W}}{\mathrm{cm} \cdot \mathrm{K}} \quad \text { Thermal conductivity of stainless steel at ambient temperature } \\
& \rho_{\mathrm{al}}:=2720 \frac{\mathrm{kg}}{\mathrm{m}^{3}} \\
& \rho_{\mathrm{sS}}:=7500 \frac{\mathrm{kg}}{\mathrm{m}^{3}} \\
& q_{\text {genss }}:=\frac{\rho_{\mathrm{Ss}}}{\rho_{\mathrm{al}}} \cdot \mathrm{q}_{\mathrm{gen}}=6.717 \frac{\mathrm{kW}}{\mathrm{cm}^{3}} \quad \begin{array}{l}
\text { Internal heat generation for stainless steel assuming } \\
\text { that the heat generation is proportional to material } \\
\text { density }
\end{array} \\
& \mathrm{L}_{\text {wallss }}:=\frac{\mathrm{h}_{\text {conv }}}{q_{\text {genss }}} \cdot\left(\mathrm{T}_{\text {smax }}-\mathrm{T}_{\text {fluid }}\right)=0.024 \mathrm{~cm} \quad \mathrm{~L}_{\text {wallss }}=9.379 \times 10^{-3} \text { in } \\
& \text { Maximum allowable wall } \\
& \text { thickness to avoid boiling } \\
& \mathrm{T}_{\mathrm{SS}}:=\frac{\mathrm{q}_{\text {genss }} \cdot \mathrm{L}_{\text {wallss }}{ }^{2}}{2 \cdot \mathrm{k}_{\mathrm{SS}}}+\mathrm{T}_{\mathrm{smax}}=112.705^{\circ} \mathrm{C} \quad \text { Maximum temperature of stainless steel }
\end{aligned}
$$





\section{Argonne}

\section{Nuclear Engineering Division}

Argonne National Laboratory

9700 South Cass Avenue, Bldg. 205

Argonne, IL 60439-5484

www.anl.gov

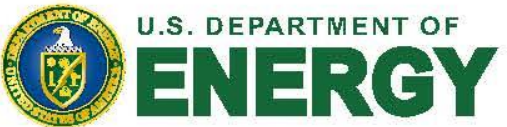

Argonne National Laboratory is a U.S. Department of Energy

laboratory managed by UChicago Argonne, LLC 